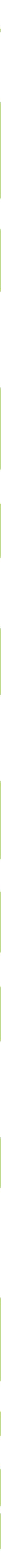


A Portada: Edificio Miguel de Mendoza \#14, CDMX México (2015) Arquitectos: PDI Diseño + construcción Fotografía: Mtro. Rodrigo García Cué (Fotógrafo) 2017 Teléfono: $+(52) 0457773359173$ rodrigogcue@gmail.com - www.rodrigogcue.com (c) (i) \$
A Orientación editorial

\section{Enfoque y alcance}

La Revista de Arquitectura (ISSN 1657-0308 Impresa y E-ISSN 2357-626X en línea) es una publicación seriada de acceso abierto, arbitrada mediante revisión por pares (doble ciego) e indexada, en donde se publican resultados de investigación originales e inéditos.

Está dirigida a la comunidad académica y profesional de las áreas afines a la disciplina. Es editada por la Facultad de Diseño y el Centro de Investigaciones (CIFAR) de la Universidad Católica de Colombia en Bogotá (Colombia).

La principal área científica a la que se adscribe la Revista de Arquitectura según la OCDE es:

Gran área: 6. Humanidades

Área: 6.D. Arte

Disciplina: 6D07. Arquitectura y Urbanismo

También se publican artículos de las disciplinas como 2A02, Ingeniería arquitectónica; 5G03, Estudios urbanos (planificación y desarrollo); 6D07, Diseño.

Los objetivos de la Revista de Arquitectura son:

- Promover la divulgación y difusión del conocimiento generado a nivel local, nacional e internacional

- Conformar un espacio para la construcción de comunidades académicas y la discusión en torno a las secciones definidas.

- Fomentar la diversidad institucional y geográfica de los autores que participan en la publicación.

- Potenciar la discusión de experiencias e intercambios científicos entre investigadores y profesionales.

- Contribuir a la visión integral de la arquitectura, por medio de la concurrencia y articulación de las secciones mediante la publicación de artículos de calidad.

- Publicar artículos originales e inéditos que han pasado por revisión de pares, para asegurar que se cumplen las normas éticas, de calidad, validez científica, editorial e investigativa.

- Fomentar la divulgación de las investigaciones y actividades desarrolladas en la Universidad Católica de Colombia.
Palabras clave de la Revista de Arquitectura: arquitectura, diseño, educación arquitectónica, proyecto y construcción, urbanismo.

Idiomas de publicación: español, inglés, portugués y francés.

Título abreviado: Rev. Arquit.

Titulo corto: RevArq

\section{Políticas de sección}

La revista se estructura en tres secciones correspondientes a las líneas de investigación activas y aprobadas por la institución, y dos complementarias, que presentan dinámicas propias de la Facultad de Diseño y las publicaciones relacionadas con la disciplina.

Cultura y espacio urbano. En esta sección se publican los artículos que se refieren a fenómenos sociales en relación con el espacio urbano, atendiendo aspectos de la historia, el patrimonio cultural y físico, y la estructura formal de las ciudades y el territorio.

Proyecto arquitectónico y urbano. En esta sección se presentan artículos sobre el concepto de proyecto, entendido como elemento que define y orienta las condiciones proyectuales que devienen en los hechos arquitectónicos o urbanos, y la forma como estos se convierten en un proceso de investigación y nuevo de conocimiento. También se presentan proyectos que sean resultados de investigación, los cuales se validan por medio de la ejecución y transformación en obra construida del proceso investigativo. También se contempla la publicación de investigaciones relacionadas con la pedagogía y didáctica de la arquitectura, el urbanismo y el diseño.

Tecnología, medioambiente y sostenibilidad. En esta sección se presentan artículos acerca de sistemas estructurales, materiales y procesos constructivos, medioambiente y gestión, relacionados con los entornos social-cultural, ecológico y económico.

Desde la Facultad. En esta sección se publican artículos generados en la Facultad de Diseño, relacionados con las actividades de docencia, extensión, formación en investigación o internacionalización, las cuales son reflejo de la dinámica y de las actividades realizadas por docentes, estudiantes y egresados; esta sección no puede superar el $20 \%$ del contenido.

Textos. En esta sección se publican reseñas, traducciones y memorias de eventos relacionados con las publicaciones en Arquitectura y Urbanismo.
Desde 1999 y hasta el 2015, la Revista de Arquitectura publicó un volumen al año, a partir del 2016 se publicarán dos números por año en periodo anticipado, enero-junio y julio-diciembre, pero también maneja la publicación anticipada en línea de los artículos aceptados (versión Post-print del autor).

La Revista de Arquitectura se divulga mediante versiones digitales (PDF, HTML, EPUB, XML) e impresas con un tiraje de 700 ejemplares, los tiempos de

Universidad Católica de Colombia (2017, enero-junio).

Revista de Arquitectura, $19(\mathrm{I})$,

I-96. Doi: 10.14718

ISSN: 1657-0308

E-ISSN: 2357-626X

Especificaciones:

Formato: $34 \times 24 \mathrm{~cm}$

Papel: Mate $115 \mathrm{~g}$

Tintas: Negro y policromía producción de estas versiones dependerán de los cronogramas establecidos por la editorial.

Los tiempos de recepción-revisión-aceptación pueden tardar entre seis y doce meses dependiendo del flujo editorial de cada sección y del proceso de revisión y edición adelantado.

Con el usuario y contraseña asignados, los autores pueden ingresar a la plataforma de gestión editorial y verificar el estado de revisión, edición o publicación del artículo.
A Canje

La Revista de Arquitectura está interesada en establecer canje con publicaciones académicas, profesionales o científicas del área de Arquitectura y Urbanismo, como medio de reconocimiento y discusión de la producción científica en el campo de acción de la publicación.

\section{Mecanismo}

Para establecer canje por favor descargar, diligenciar y enviar el formato: RevArq FP20 Canjes

\section{Contacto}

Dirección postal:

Avenida Caracas No. 46-72.

Universidad Católica de Colombia

Bogotá D.C.(Colombia)

Código postal: 111311

Facultad de Diseño

Centro de Investigaciones (CIFAR).

Sede El Claustro. Bloque "L", 4 piso

Diag. 46a No. $15 \mathrm{~b}-10$

Editor, Arq. César Andrés Eligio Triana

Teléfonos:

+57 (1) $3277300-3277333$

Ext. 3109; 3112 o 5146

Fax: +57 (1) 2858895
Correo electrónico:

revistadearquitectura@ucatolica.edu.co cifar@ucatolica.edu.co

Página WEB:

www.ucatolica.edu.co

vínculo Revistas científicas

http://publicaciones.ucatolica.edu.co/ revistas-cientificas

http://editorial.ucatolica.edu.co/ojsucatolica/ revistas_ucatolica/index.php/RevArq 
Universidad Católica de Colombia

Presidente

Édgar Gómez Betancourt

Vicepresidente - Rector

Francisco José Gómez Ortiz

Vicerrector Jurídico

Edwin de Jesús Horta Vásquez

Vicerrector Administrativo

Édgar Gómez Ortiz

Decano Académico

Elvers Medellín Lozano

Directora de Investigaciones

Elisa Urbina Sánchez

Directora Editorial

Stella Valbuena García
Facultad de Diseño

Decano

Werner Gómez Benítez

Director de docencia

Jorge Gutiérrez Martínez

Directora de extensión

Adriana Pedraza Pacheco

Director de investigación

Hernando Verdugo Reyes

Director de gestión de calidad

Augusto Forero La Rotta

Comité asesor externo

Facultad de Diseño

Alberto Miani Uribe

Giovanni Ferroni Del Valle

Samuel Ricardo Vélez

Lorenzo Castro
Facultad de Diseño

Centro de Investigaciones - CIFAR

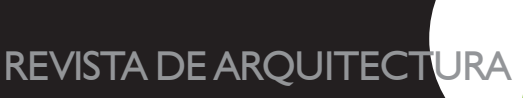

, tectura

Revista de acceso abierto, arbitrada e indexada

Publindex Categoría B. Índice Bibliográfico Nacional IBN. Colombia.

Esci. Emerging Source Citation Index

Doaj. Directory of Open Access Journ

Ebsco. EBSCOhost Research Databases. Estados Unidos.

Proquest. ProQuest Research LibraryProQuest Research

Library ProQuest Research Library. Estados Unidos

Redalyc. Red de Revistas Científicas de América Latina

y el Caribe, España y Portugal. Sistema de Información

Científica. México.

Redib. Red Iberoamericana de Innovación y Conocimiento Científico. España

Latindex. Sistema Regional de Información en Línea para Revistas Científicas de América Latina, el Caribe, España y Portugal (Directorio y catálogo). México.

Clase. Base de datos bibliográfica de revistas de ciencias sociales y humanidades. Universidad Autónoma México. Dialnet. Fundación Dialnet - Biblioteca de la Universidad de La Rioja. España.

Actualidad Iberoamericana. (Índice de Revistas) Centro de Información Tecnológica (CIT). Chile.

Arla. Asociación de revistas latinoamericanas de arquitectura.

Editorial

Av. Caracas N 46-72, piso 5

@ucatolica.edu.co

whw.ucatolica.edu.co

Impresión:

JAVEGRAF

Calle 46A N $82-54$ Int. 2

Bogotá, D. C., Colombia

http://www.javegraf.com.co/index.php

Junio de 2017
Revista de Arquitectura

Director

Werner Gómez Benítez

Editor

César Eligio-Triana

Editores de sección

(4) Myriam Stella Díaz Osorio

(4) Carolina Rodríguez Ahumada

(4) Anna Maria Cereghino Fedrigo

Consejo editorial

Werner Gómez Benítez

Jorge Gutiérrez Martínez

César Eligio-Triana

Hernando Verdugo Reyes

\section{Equipo editorial}

Coordinadora editorial

María Paula Godoy Casasbuenas mpgodoy@ucatolica.edu.co

Diseño y montaje

Juanita Isaza

juanaisaza@gmail.com

Traductoras

Inglés

Erika Tanacs

etanacs25@gmail.com

Portugués

Roanita Dalpiaz

roanitad@gmail.com

Correctora de estilo

María José Díaz Granados M.

mariajose_dgm@yahoo.com.co

Página Web

Centro de investigaciones (CIFAR)

Distribución y canjes

Claudia Álvarez Duquino

calvarez@ucatolica.edu.co
Comité editorial y científico

Cultura y espacio urbano

Carlos Mario Yory, PhD

Universidad Católica de Colombia. Bogotá, Colombia

Sonia Berjman, $\mathrm{PhD}$

ICOMOS-IFLA, Buenos Aires, Argentina

Juan Carlos Pérgolis, MSc Universidad Piloto de Colombia. Bogotá, Colombia

Beatriz García Moreno, PhD

Universidad Nacional de Colombia. Bogotá, Colombia

Proyecto arquitectónico y urbano

Jean-Philippe Garric, PhD, HDR

Université Paris I Panthéon-Sorbonne. Paris, Francia

Debora Domingo Calabuig, PhD

Universidad Politécnica de Valencia, España

Hugo Mondragón López, PhD

Pontificia Universidad Católica de Chile. Santiago, Chile

Juan Pablo Duque Cañas, PhD

Universidad Nacional de Colombia. Bogotá, Colombia

Jorge Grané del Castillo, Msc

Universidad de Costa Rica. San José, Costa Rica

Tecnología, medioambiente y sostenibilidad

Mariano Vázquez Espí, PhD.

Universidad Politéenica de Madrid, España.

Luis Carlos Herrera Sosa, PhD

Universidad Autónoma de Ciudad Juárez, México

Claudio Varini, PhD

Universidad Católica de Colombia. Bogotá, Colombia

Luis Gabriel Gómez Azpeitia, PhD

Universidad de Colima. Colima, México 

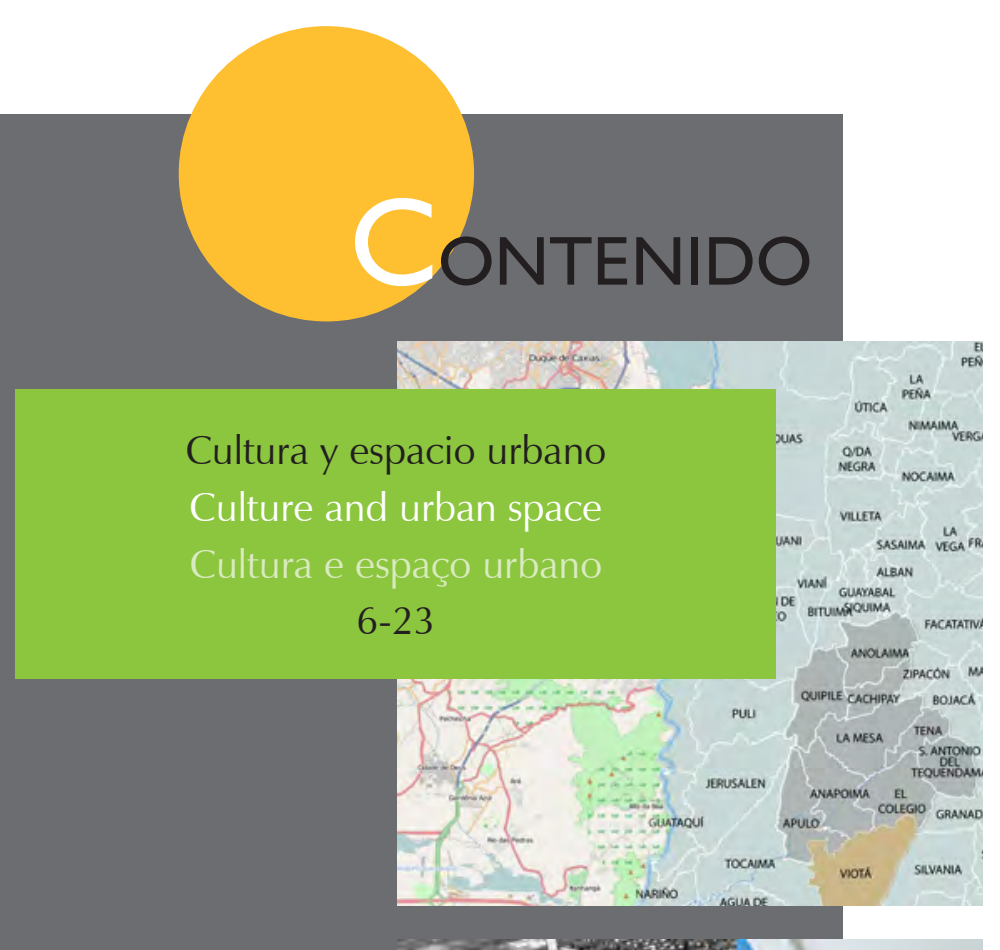

Proyecto arquitectónico y urbano

Architectural and urban project

Projeto arquitetônico e urbano

$$
\text { 24-41 }
$$

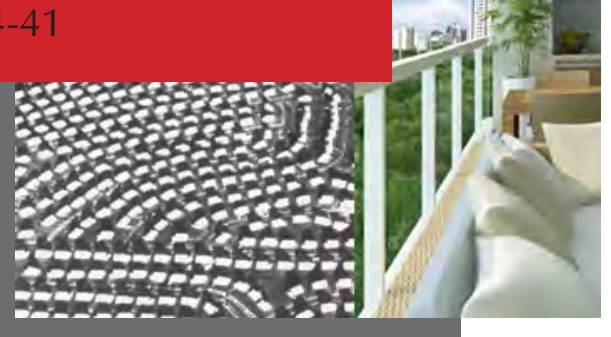

.

Tecnología, medioambiente y sostenibilidad

Technology, environment and sustainability Tecnologia, meio ambiente e sustentabilidade 42-69
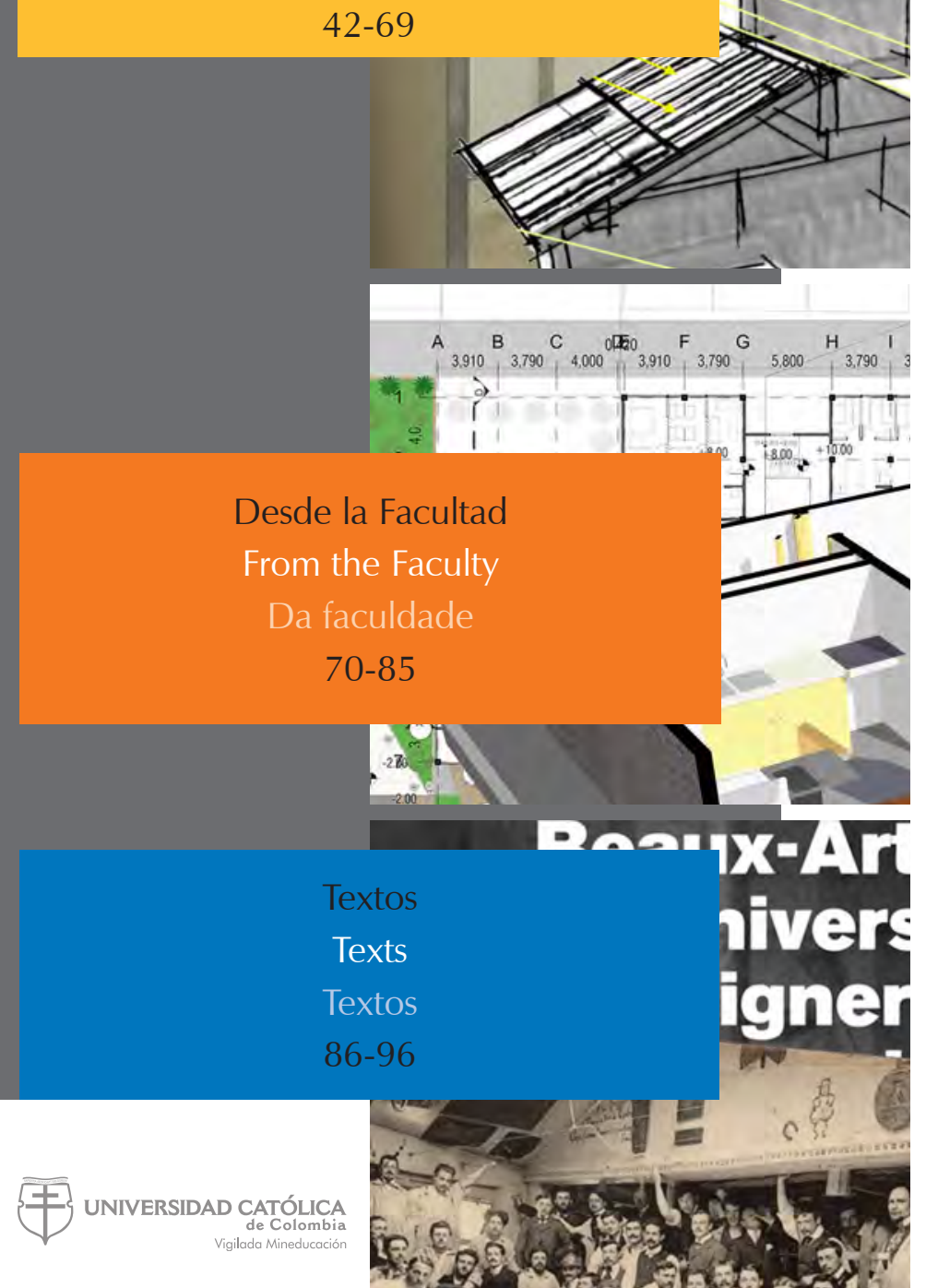

\section{A favela é um cenário:}

tematização e cenarização nas favelas cariocas

Sergio-Moraes-Rego Fagerlande

Pág. 6

Gestión cultural del patrimonio en Viotá,

\section{Cundinamarca}

Diana María Blanco-Ramírez

Pág. 14

De la utopía a la distopía doméstica

La creación de la vivienda modelo norteamericana

Carlos Santamarina-Macho

Pág. 24

La varanda gourmet brasileña:

arquitectura hedonista y distinción social

Bruno Cruz-Petit

Alejandro Pérez-Duarte Fernández

Pág. 33

Techo plantado como dispositivo de

climatización pasiva en el trópico

Iván Osuna-Motta

Carlos Herrera-Cáceres

Oswaldo López-Bernal

Pág. 42

Criterios de integración de energía solar activa en arquitectura

Potencial tecnológico y consideraciones proyectuales

Esteban Zalamea-León

Felipe Quesada

Pág. 56

Prototipos flexibles

Proyecto habitacional en el barrio popular

Buenos Aires (Soacha)

Mildred Paola Laiton-Suárez

Pág. 70

La pedagogía del taller en la enseñanza de la arquitectura

Una aproximación cultural y material al caso francés (siglos XIX y XX)

Guy Lambert

Traductores:

Andrés Ávila-Gómez

Diana Carolina Ruiz

Pág. 86 


\section{Gestión cultural del patrimonio en Viotá, Cundinamarca}

\section{Diana María Blanco-Ramírez}

Universidad Piloto de Colombia, Bogotá (Colombia)

Facultad de Arquitectura y Artes
Blanco-Ramírez, D. (2017). Gestión cultural del patrimonio en Viotá, Cundinamarca. Revista de Arquitectura, $19(1), 14-23$. doi: http://dx.doi.org/10.14718/ RevArq.2017.19.1.900

\section{(c) $(1) \Theta$}

http://dx.doi.org//0.14718/RevArq.2017.19.1.900
Arquitecta, Universidad Piloto de Colombia, Bogotá (Colombia). Especialista en Administración y Planificación del Desarrollo Regional del Cider.

Magíster en Restauración Arquitectónica y recuperación edilicia, urbana y ambiental, Universitá degli Studi RomaTre, Roma (Italia).

PhD (c) en Sistemas de Información Geográfica, Universidad Pontificia de Salamanca, Campus Madrid (España).

Evaluador de proyectos de intervención de la Subdirección Técnica de Intervención del Instituto Distrital de Patrimonio Cultural, Bogotá (Colombia).

Docente del Programa de Arquitectura, Facultad de Diseño, Universidad Católica de Colombia, Bogotá (Colombia).

(1D) http://orcid.org/0000-000I-5590-9017

dianita.blanco@gmail.com

\section{Resumen}

El proyecto presentado se realizó en el municipio de Viotá, Cundinamarca, y busca fortalecer la creación de planes productivos que potencien las relaciones regionales y que, a su vez, permitan la recomposición del tejido social desde el punto de vista de la arquitectura. La investigación parte del reconocimiento de la importancia y el valor de los elementos de tipo patrimonial, que a causa del conflicto armado se vieron afectados y debilitados en las últimas dos décadas. El documento describirá las dos primeras fases del método de investigación que fueron: la identificación, la caracterización y el inventario de los elementos con valor patrimonial que se encuentran en el área rural del municipio, como son: haciendas cafeteras, caminos reales y petroglifos, que de acuerdo con el estudio realizado podrían articularse dentro de un itinerario cultural o paisaje industrial, haciendo especial énfasis en las evidencias encontradas en relación con las haciendas cafeteras como puntos de articulación.

Palabras clave: patrimonio cultural, bienes de interés cultural, inventario de bienes, haciendas cafeteras, gestión del patrimonio.

\section{Cultural heritage management in Viotá, Cundinamarca}

\section{Abstract}

This paper aims to present the progress made in the research project carried out in the municipality of Viotá in 2014, as part of a macro-project between several faculties of the Universidad Piloto de Colombia realized during the period 2012-2015, which sought to strengthen the creation of productive projects to improve regional relations, and which allowed for the reconstruction of the social fabric from the perspective of architecture. The research starts with recognizing the importance and value of patrimonial elements that, due to the armed conflict, were affected and weakened in the last two decades. In the first two phases, the research method was identification, characterization and inventory of items of heritage value in the rural area of the municipality, such as coffee plantations, roya trails, and petroglyphs, in order to organize them within a cultural itinerary or an industrial landscape, with a particular emphasis on the evidence found regarding coffee plantations as articulating points.

Keywords: Cultural heritage, cultural property, property inventories, heritage management.

\section{Gestão cultural do patrimônio em Viotá, Cundinamarca}

\section{Resumo}

O projeto apresentado foi realizado no município de Viotá (Cundinamarca, Colômbia). Seu objetivo foi fortalecer a criação de plantas produtivas que potencializem as relações regionais e que, por sua vez, permitam a recomposição do tecido social do ponto de vista da arquitetura. A pesquisa parte do reconhecimento da importância e do valor dos elementos de tipo patrimonial, que, por causa do conflito armado, se viram afetados e enfraquecidos nas últimas duas décadas. $\mathrm{O}$ documento descreve as duas primeiras fases do método de pesquisa que foram: I) identificação e 2) caracterização e inventário dos elementos com valor patrimonial que se encontram na área rural do município, como são: fazendas cafeeiras, caminhos reais e petróglifos, que, de acordo com o estudo realizado, poderiam ser articulados dentro de um roteiro cultural ou paisagem industrial, enfatizando as evidências encontradas em relação às fazendas cafeeiras como pontos de articulação.

Palavras-chave: bens de interesse cultural, fazendas cafeeiras, gestão do patrimônio, inventário de bens, patrimônio cultural.

\section{Introducción}

Este documento muestra los resultados de las fases 1 y 2 del subproyecto de investigación "Gestión cultural del patrimonio y paisaje cultural", de la Facultad de Arquitectura y Artes, en conjunto con la Facultad de Economía, como parte del macroproyecto que la Universidad Piloto de Colombia realizó en el municipio de Viotá, en el periodo 2012-2015, el cual busca fortalecer la construcción de proyectos productivos que potencialicen la relaciones regionales y permitan la recomposición del tejido social que, a causa del conflicto armado, se vio afectado y debilitado en las últimas dos décadas. El estudio se centra en el patrimonio cultural presente en el municipio, como caminos reales, petroglifos, haciendas cafeteras, maquinaria relacionada con el procesamiento del café, etc. (Figura 1).

Puesto que el objeto de estudio del grupo de investigación ${ }^{1}$ es la gestión cultural de patrimonio, es importante definir el término "patrimonio cultural" como legado del pasado y herencia para las generaciones futuras, para que de él puedan aprender las mismas. El patrimonio incluye lugares, objetos y tradiciones que se desean conservar, valorados porque son ancestrales, parte de la vida cotidiana, o porque son ejemplos irreemplazables de una forma de vida en un momento histórico.

La hipótesis a partir de la cual surge este trabajo es la comprensión del patrimonio cultural desde el concepto de valor, entendido como el sentido o la importancia del lugar, que puede ser histórica o arquitectónica, así como la imagen del territorio a través de las dinámicas de la población y su cotidianidad, a fin de encontrar el significado del lugar mediante la caracterización del territorio, haciendo una revisión del pasado y de las costumbres que permitieron establecer la identidad del área sujeta a estudio. Gracias a esto es posible una aproximación a nivel municipal y regional de las estrategias que permitan hacer una inserción del municipio de Viotá en la región de Cundinamarca, desde las dimensiones del desarrollo cultural, ambiental, político, social, económico. En este documento se considerarán los alcances de la Fase 1, identificación, y Fase 2, caracterización (Figura 2).

1 Grupo de investigación "Identidad y patrimonio cultural". 


\section{Justificación}

Se hace necesario propiciar y realizar una caracterización del territorio que permita conocer y valorar el patrimonio cultural y natural del municipio, para que pueda ser reconocido por los habitantes de Viotá y por los foráneos. El tema del turismo fue abordado por el economista Oscar Javier Martínez Herrera (2016), de la Facultad de Economía, quien se aproximó a la cuestión desde la búsqueda de fuentes fiscales e incentivos económicos y de financiación que permitan la conservación del patrimonio cultural, teniendo el turismo como fuente alternativa de ingresos para la conservación de los mismos. Por tal motivo, esta investigación se enfoca, desde la visión arquitectónica, en la identificación, caracterización y valoración de los bienes de interés cultural (BIC), para su posterior inventario.

Se toma como punto de partida la Ley General de Cultura (Ley 1185 de 2008), en su artículo 1, la cual establece que el patrimonio es lo que permite generar sentido y lazos de pertenencia, identidad y memoria para un grupo o colectivo humano; dicha ley establece que el patrimonio debe ser protegido, recuperado, conservado, ser sostenible en el tiempo y divulgado, con el fin de que sirva como testimonio de la identidad cultural nacional; asimismo, define los estímulos para los bienes de interés cultural que sean declarados, de acuerdo con los criterios de valoración que establece el Sistema Nacional de Patrimonio Cultural de la Nación, definidos en el Título 2 del Decreto 763 de 2009.

จ Figura 1. Paisaje de hacienda cafetera en Viotá, Cundinamarca Fuente: elaboración propia, 2014.
Hoy en día, el patrimonio cultural y natural se hace visible con los itinerarios culturales y patrimoniales (Icomos, 2008a), que son una de las alternativas más fuertes y modernas para la defensa y el enriquecimiento de la identidad territorial. Estos itinerarios permiten comprender los elementos patrimoniales en su contexto, así como los intercambios humanos que a través de las vías de comunicación de un lugar reflejan las diferentes relaciones y etapas históricas que se llevaron a cabo (Icomos, 2008b).

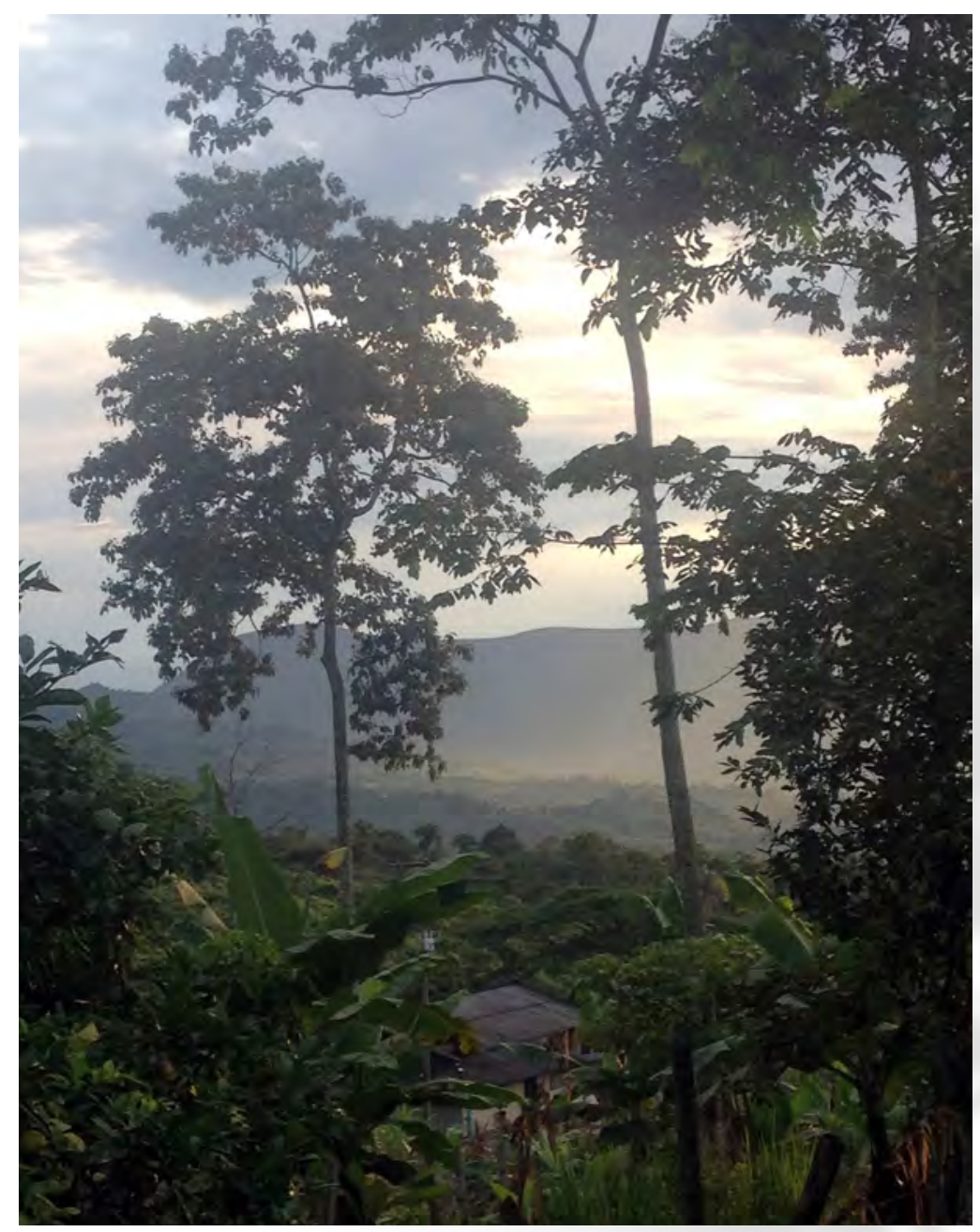

Mapa conceptual investigación Gestión cultural del patrimonio

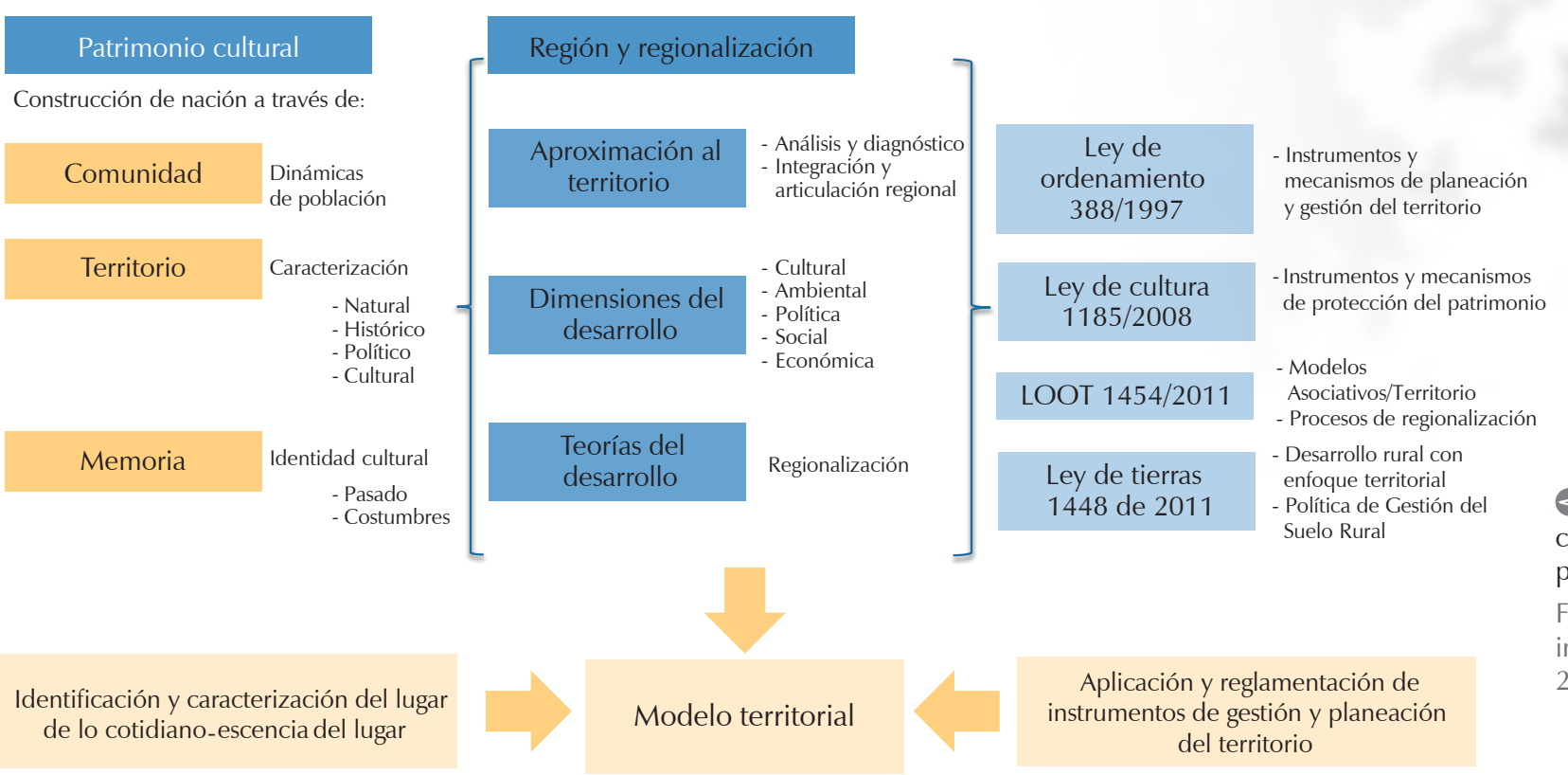

Figura 2. Mapa Gestión cultural del patrimonio y paisaje cultural uente: Dayra Vargas, investigadora principal, 2013 
De acuerdo con esta idea, la creación de circuitos culturales que contribuyan con la identificación, comprensión y conexión de $\operatorname{los}^{2} \mathrm{BIC}$ que hacen parte de un territorio ayudan a establecer conjuntos más grandes de bienes culturales con características comunes, con el fin de desarrollar el turismo cultural que facilita que este sea sostenible gracias a la cultura y el diseño arquitectónico, puesto que alrededor de las manifestaciones culturales se desarrollan industrias organizadas que generan ingresos y empleo. Por ello, el turismo cultural es una alternativa de desarrollo (Throsby, 2008, pp. 181-183).

Es importante resaltar la importancia del patrimonio arquitectónico presente en Viotá por su valor histórico, como pieza fundamental para la construcción de la identidad del municipio, creando alternativas de inclusión y participación comunitaria que logren que la comunidad genere sentimientos positivos de valoración y respeto hacia los elementos patrimoniales existentes. Con respecto al legado, es importante que el patrimonio se pueda transmitir o heredar a futuras generaciones, que personas que no están directamente involucradas lo puedan disfrutar, y que este genere consumo cultural entendido como la experiencia de conocer algo y disfrutarlo (valor de uso) (Throsby, 2008).

Por tanto, es de vital importancia identificar o crear en las áreas rurales las políticas públicas que permitan el desarrollo territorial y urbano a través del patrimonio cultural y, de ser posible, a través de los diferentes instrumentos económicos que están previstos para incentivar la protección del patrimonio, entre los que se destacan el cobro del impuesto del valor agregado (IVA) a la telefonía celular, el aforo y la viabilización de proyectos, incentivos tributarios a propietarios de bienes de interés cultural, y financiación de servicios especiales (Ministerio de Cultura, 2010, pp. 73-84).

\section{Objetivo}

El objetivo principal de este proyecto de investigación es reconocer y recuperar el patrimonio cultural como recurso para la gestión del territorio en los municipios con población menor a 15.000 habitantes $^{3}$; asimismo, se pretende implementar el desarrollo regional con un enfoque territorial, con el fin de generar cohesión social, cultural y territorial. Este objetivo general se logrará por medio de:

2 El bien de interés cultural es una categoría de la Ley 397 de 1997 que permite identificar los bienes del patrimonio cultural, muebles o inmuebles, que por su valor excepciona requieren de un tratamiento especial (Ministerio de Cultura, 2011, p. 19).

3 Municipios que por número de habitantes cuentan con esquema de ordenamiento territorial (EOT), de 0 a 30.000 habitantes.
1. La caracterización conceptual del paisaje industrial o itinerario cultural, estableciendo cuál es el mejor caso que se podría aplicar a Viotá.

2. La elaboración de reseñas históricas e inventarios a fin de definir criterios de valoración de los bienes de interés cultural encontrados en el municipio.

3. Realizar un marco teórico a partir de las siguientes variables: región productiva, territorio y paisaje cultural, objetivo y enfoques de la mesa de ruralidad, patrimonio cultural material e inmaterial, identidad y sostenibilidad.

4. Elaborar esquemas, cartografía, planimetría para publicaciones, para apropiación del conocimiento por parte de la comunidad y de la investigación.

\section{Metodología}

La metodología planteada para la consecución de los objetivos propuestos dentro del proyecto de investigación partió de una revisión del marco normativo existente a nivel nacional e internacional para, a partir del mismo, plantear las fases necesarias para caracterizar el territorio y lograr recuperar el valor intangible del municipio de Viotá aprovechando sus diversos atractivos culturales y naturales.

\section{Las normas}

La identificación del patrimonio cultural de un territorio debe tener en cuenta los parámetros que define la Unesco en la Carta de Atenas (Unesco, 1931) y la Carta de Venecia (Unesco, 1964), donde se habla de crear planes de manejo para que el patrimonio cultural tenga un cuidado permanente por parte de la comunidad y sea sostenible durante su permanencia en el tiempo. Así como lo hace la Norma de Quito (Icomos, 1967), que aplicada en el contexto latinoamericano, dice que se debería hacer un plan sistemático de revalorización, en función del desarrollo económico y social, con infraestructura para el desarrollo regional. Además, el interés social y la acción cívica respaldan la puesta en valor de las zonas históricas ambientales y la determinación de los usos y las inversiones en obras de restauración, conservación e infraestructura, a través de un régimen especial de protección, reglamentando las zonas adyacentes y las medidas de mantenimiento.

Para poder cumplir con estas tareas, el punto de partida es la identificación, el inventario, la valoración y la declaratoria de los bienes de interés cultural que, de acuerdo con el Sistema Nacional de Patrimonio Cultural de la Nación en el Decreto 763 de 2009, establecen los criterios de valoración para poder llegar a la declaratoria: antigüedad, autoría, autenticidad, constitución del bien, forma, estado de conservación, contex- 
to ambiental, contexto urbano, contexto físico y representatividad y contextualización sociocultural (Título 2, art. 6). Así como los valores atribuibles a los bienes tales cómo:

\footnotetext{
- Valor Histórico: “... cuando se constituye en documento o testimonio para la reconstrucción de la historia [...]. Es la asociación directa del bien con épocas, procesos, eventos y prácticas políticas, económicas, sociales y culturales".

- Valor Estético: “... cuando se reconocen en este atributos de calidad artística, o de diseño, que reflejan una idea creativa en su composición, en la técnica de elaboración o construcción, así como en las huellas de utilización y uso dejadas por el paso del tiempo".

- Valor simbólico: “... cuando manifiesta modos de ver y de sentir el mundo. [...] tiene un fuerte poder de identificación y cohesión social" (Ministerio de Cultura, 2005, pp. 36-43).
}

Una vez establecidos los criterios de valoración para los BIC, y su identificación para poder comprender el territorio, conocer su historia e incrementar el sentido de apropiación de la comunidad, es importante que de manera concertada entre los diferentes actores se formulen Planes Especiales de Manejo y Protección (PEMP) para los BIC hipotéticamente presentes en el territorio, considerando que deben determinar (Ministerio de Cultura, 2011, pp. 20-21):

1. Las condiciones para la articulación del BIC en su contexto físico y entorno sociocultural, partiendo del principio de que hay que conservar sus valores, mitigar sus riesgos y aprovechar sus potencialidades.

2. Las acciones de carácter preventivo o correctivo para su conservación.

3. Las condiciones para su mantenimiento y conservación.

4. Los mecanismos para su recuperación y sostenibilidad.

5. Las estrategias para propiciar el conocimiento y la apropiación social del BIC por la comunidad.

En Colombia, y gracias al reconocimiento de la Convención de la Unesco de 1972, el patrimonio cultural se integra al natural para que se genere en el territorio un desarrollo local y turístico; el patrimonio natural debe ser entendido como:

\begin{abstract}
...los monumentos naturales constituidos por formaciones físicas, biológicas, geológicas y fisiográficas, así como las zonas que constituyen el hábitat de especies animales o vegetales amenazadas y los lugares o áreas naturales estrictamente delimitadas, que tengan un valor universal excepcional desde el punto de vista de la ciencia, de la conservación o de la belleza natural (art. 2, p. 2).
\end{abstract}

La legislación nacional, por medio de la Ley 388 de 1997, define los instrumentos de gestión aplicables a todos los municipios del país, clasificando los planes de ordenamiento en tres tipos de acuerdo con el número de pobladores, y, del mismo modo, el Consejo Nacional de Política Económica y Social (Conpes, 2004) hace la revisión del proceso de planeación en el orden nacional, destacando que el $65 \%$ de los municipios del país no cuenta con la capacidad técnica y operativa de intervenir el territorio, y hace evidente la falta de estudios técnicos básicos que hagan posible elaborar diagnósticos y procesos de planeación que aporten a la elaboración de los esquemas básicos de ordenamiento.

Ante esta situación, el Conpes (2004) plantea incluir los PEMP como un instrumento que se puede aplicar a los territorios que contienen valor paisajístico, cultural y patrimonial, como un instrumento de planeación que aporte al desarrollo de los asentamientos rurales; de manera que este proyecto de investigación, en alguna de sus fases futuras, se plantea revisar, ajustar, complementar y proyectar instrumentos de gestión para asentamientos rurales en un contexto general, definiendo el alcance aplicativo a los municipios de menor jerarquía. En este sentido, el Conpes (2014), Ley 3803 de 2014, propuesto para el caso del paisaje cultural cafetero con declaratoria mundial, sirve de base metodológica para la caracterización y contextualización en otros casos similares dentro del territorio nacional.

\section{Fases}

Para poder caracterizar el territorio y recuperar el valor intangible del municipio de Viotá aprovechando sus diversos atractivos culturales y naturales, se plantearon las siguientes fases según la figura 3:

Fase 1. Identificación. Reconocimiento en terreno del territorio regional, urbano y rural, identificando centros regionales, subregionales y municipios que convergen en el área de influencia, para de este modo poder determinar cuáles son los bienes susceptibles de ser inventariados.

Fase 2. Caracterización. Análisis y caracterización de la región a partir de la conformación de la estructura ecológica principal, conexión con sistemas ambientales comprometidos con el patrimonio y el paisaje del territorio, el sistema de movilidad, la conectividad y la articulación con el área de influencia y con la región, la ocupación, el uso y la actividad del suelo, la propiedad y distribución de tierras, el sistema de equipamientos y las potencialidades propias del territorio. Del mismo modo, para aquellos bienes que entran dentro del inventario, se procederá a hacer las fichas que permitan establecer por qué deberían ser considerados BIC.

Fase 3. Diagnóstico.

Fase 4. Formulación del instrumento de gestión. 
(1) Figura 3. Fases del proyecto de Investigación

Fuente: elaboración propia, 2014

Gestión cultural del patrimonio y paisaje cultural

Fase 1

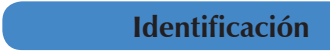

Fase 2

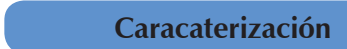

Fase 3

\begin{tabular}{|c|}
\hline Diagnóstico \\
\hline Formulación de \\
instrumentos de gestión \\
\hline
\end{tabular}

Fase 4

\section{Resultados}

De acuerdo con lo propuesto en la metodología se procedió a abordar las dos primeras fases de la siguiente forma:

\section{Fase 1. Identificación}

El municipio de Viotá se encuentra a $86 \mathrm{~km}$ de Bogotá, en el departamento de Cundinamarca, provincia del Tequendama, colinda con dos de las provincias más importantes del departamento: Alto Magdalena y Sumapaz. Está localizado sobre la que sería una de las primeras carreteras nacionales que permitía conectar a la capital directamente con el suroccidente del país a principios del siglo XX: la troncal del Tequendama que, a causa de la topografía, fue sustituida por la vía Bogotá-Anapoima-Girardot.

Gracias a su clima y geografía, Viotá permite que en una pequeña área geográfica se puedan encontrar diversos pisos térmicos; actualmente se dedican a la producción de otros productos agrícolas como: cítricos, maíz, plátano y mango, lo que permitió ampliar sus ciclos productivos, situación que fue favorable en la conocida crisis del café de 1989-1994, donde a través de los otros productos resistieron dicho embate (Tocancipá-Falla, 2006). Se caracteriza por ser un importante centro agrícola en la región, con una tasa decreciente de población. Del mismo modo, por no presentar políticas conjuntas de planeación territorial, la región tiene algunos asentamientos que no se encuentran articulados entre sí, con precarias redes de servicios y no cuentan con los recursos y equipamientos suficientes para suplir las necesidades de sus habitantes, por lo que estos se ven obligados a emigrar en busca de una mejor calidad de vida y más oportunidades.

Esta situación ya ha sido identificada por el gobierno local, que en su Esquema de Ordenamiento Territorial (EOT) (Decreto 69 de 2011) y Plan de Desarrollo (Alcaldía de Viotá, 2012) pretende emprender proyectos de nueva ruralidad y agroturismo que les permitan atraer turistas e inversionistas a la zona, como ha ocurrido en la zona del eje cafetero y en otros departamentos del país.

Es por este motivo que la población civil ya se está organizando en asociaciones de productores para tener mayor visibilidad y que de esta manera sean más fácilmente escuchados. Desde el punto de vista teórico, este trabajo en equipo entre la administración pública del municipio y la comunidad estaría relacionado con el desarroIlo humano que se centra en aumentar las capacidades de las personas y su interacción con la sociedad, donde cada persona interactúa con creencias, valores, lenguas y tradiciones (Throsby, 2008). Otra de las características que hace que Viotá sea estratégico respecto a sus vecinos es su riqueza hídrica, por lo que junto con su gradiente altitudinal constituye uno de los territorios más fértiles de la región, con un $68 \%$ de área rural.

Los resultados obtenidos y las evidencias de objetivos y enfoques de la Mesa de ruralidad, patrimonio cultural material e inmaterial, identidad y 
sostenibilidad, participación ciudadana y colectividad, han permitido que la experiencia previa que tiene la Facultad de Arquitectura en otros casos de estudio similares en algunos departamentos del país como Boyacá y Tolima, fueran tomados como modelo en la propuesta de metodología por seguir.

Del mismo modo, se puede resaltar su potencial como elemento para generar turismo cultural a partir de las haciendas inventariadas, ya que al no depender directamente de recursos públicos o decisiones políticas, permiten generar dinámicas económicas importantes actualmente en el municipio. Es importante agregar que el turismo cultural no debe romper con los principios de sustentabilidad y de preservación (Throsby, 2008).

\section{Haciendas cafeteras en Viotá}

Al hacer la aproximación al territorio de Viotá desde el punto de vista patrimonial es posible notar el valor que tienen las antiguas haciendas cafeteras en el territorio y que actualmente se encuentran en deterioro. Estas haciendas son evidencia de un modelo de distribución del territorio que existe desde el siglo XVIII aproximadamente.

El sistema de haciendas en Colombia surge partir de la segunda mitad del siglo XVIII, cuando el rey de España comienza conceder el dominio y el derecho de explotación de las tierras, aunque no la tenencia, buscando frenar el predominio de los latifundios, que pudieron sobrevivir hasta el siglo XIX gracias a los matrimonios por conveniencia entre familias de terratenientes (Téllez, 1997). Históricamente, en Viotá existían tres importantes latifundios: La Neptuna, San Miguel de Amantá y Calandaima, en los cuales se comenzaron a consolidar las grandes haciendas.

El sistema de haciendas vino a reemplazar la encomienda, otorgando grandes extensiones de tierra a los terratenientes (Colmenares, 1987). Este cambio en las costumbres agrícolas permitió a los hacendados manejar los mercados locales y operar en amplias porciones de territorio, obteniendo en muchos casos manos de obra gratuita a cambio de protección. A partir del siglo XIX, en Viotá comienza el cultivo del café en los tres latifundios mencionados, y a principios del siglo XX fue un modelo útil para comenzar a comerciar con otros países productos agrarios que no se encontraban allí.

Una de las determinantes a la hora de elegir dónde localizar las haciendas era la facilidad de obtención o cercanía de los suministros de agua, los caminos de acceso y la facilidad de obtención de materiales para construirla, puesto que el transporte y los problemas de accesibilidad podían subir los costos. Normalmente eran cons-

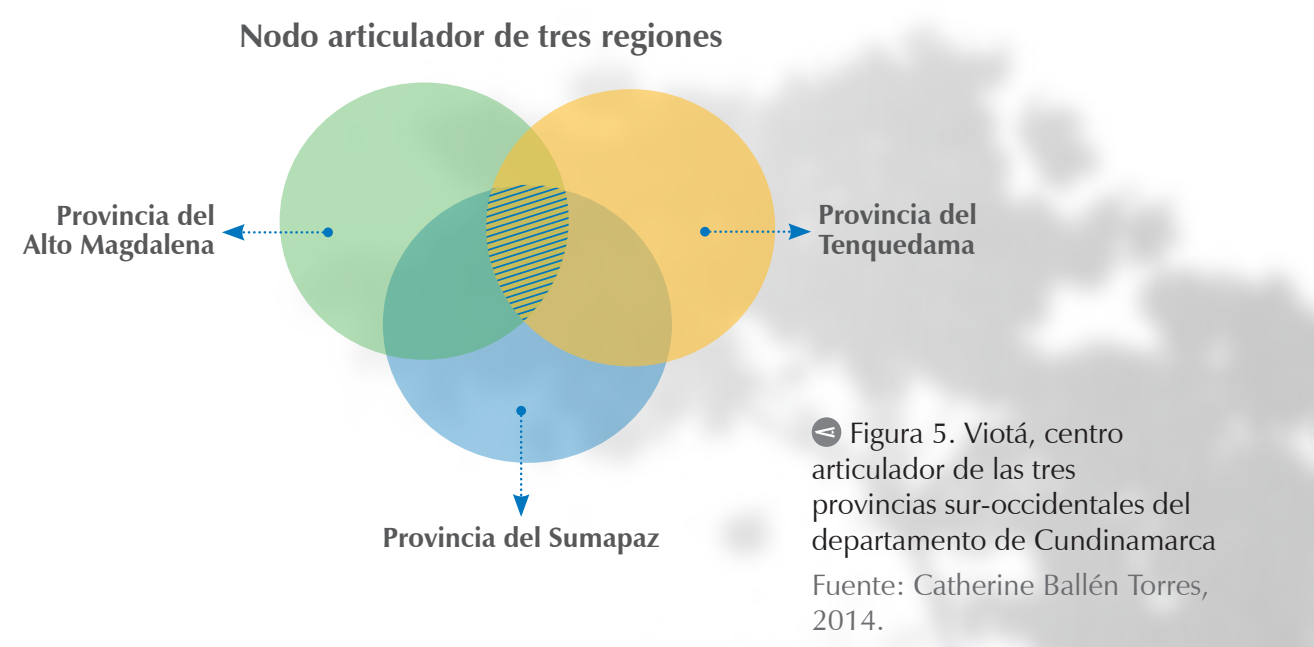

truidas por maestros constructores, albañiles y carpinteros; esto explica por qué son tan diferentes las unas de las otras, y es difícil realizar una clasificación.

El interés en realizar esta clasificación tipológica e inventario está relacionado con la necesidad por parte de los propietarios de buscar otras fuentes de financiación para mantener sus haciendas, que podrían ser los recursos provenientes del IVA por telefonía al poder ser declaradas bien de interés cultural del ámbito nacional.

\section{Clasificación tipológica de las haciendas}

Para comenzar a abordar el tema del inventario de las haciendas cafeteras identificadas hasta momento en el territorio de Viotá, se procedió a hacer una clasificación morfológica y tipológica, de materiales de construcción, respuesta a factores climáticos y ambientales, etc. En cuanto a las evidencias encontradas se decidió desistir de la identificación, puesto que al realizar la revisión del estado actual se encontró dificultad a la hora de realizar la clasificación debido a que en la mayoría de los casos las haciendas tenían características muy específicas y particulares que hacía difícil generalizar. De acuerdo con el punto de vista del arquitecto e historiador Germán Téllez (1997), experto en el tema de las haciendas neogranadinas en Colombia, al ser las haciendas creadas como herramientas de trabajo y no como obras de arte, es inválida cualquier clasificación tipológica ya que cada caso es muy particular y aunque tienen elementos en común, al entrar en el análisis de los detalles se encuentra que son diferentes.

De este modo, simplemente se procedió a inventariar, a establecer los criterios de valoración de las haciendas, y a realizar comparaciones tipológicas con las que se encuentran en algunos parajes del paisaje cultural cafetero (PCC) y otras regiones de Colombia destinadas al cultivo del café, para tratar de establecer similitudes y diferencias. Aunque de momento aún se está indagando sobre este tema. 
Para realizar el inventario de las haciendas cafeteras en Viotá se realizaron visitas con el equipo interdisciplinar, en compañía de los hacendados o de los administradores de las haciendas. En la mayoría de los casos, las visitas se realizaron solo en la parte exterior de las haciendas, puesto que por la historia reciente del municipio aún existe cierto miedo y desconfianza ante las personas que vienen de fuera. El orden de las visitas se estableció principalmente a partir de dos determinantes: la primera fue la accesibilidad, el estado de las vías y la distancia desde el casco urbano de Viotá hasta la hacienda; y el segundo fue la disponibilidad y voluntad por parte de los propietarios o administradores de permitir el acceso al equipo de trabajo.

Una vez realizado un levantamiento arquitectónico preliminar y de información gráfica, se procedió a elaborar unas fichas de inventario de acuerdo al formato establecido por el Ministerio de Cultura (2005), y posteriormente se realizó un esquema de análisis (Figura 6) para establecer algunos elementos comunes. Los ítems que se tuvieron en cuenta para la elaboración de dicho esquema son:

1. Localización: fue la primera determinante a la hora de realizar las visitas y los recorridos, puesto que uno de los problemas en la zona es la accesibilidad y el estado de las vías.

2. Años de construcción, en el caso de poder determinarlo exactamente.

3. Programa arquitectónico: que estaba directamente relacionado con las dimensiones de la parcela, con la cantidad de matorrales de café, y la función del área de trabajo. Puesto que esto directamente se refleja en el tamaño de la casa de hacienda.

4. Planimetría: distribución en planta de la casa principal.

5. Características particulares: organización espacial, elementos diferenciador-es.

6. Pertenecientes a alguna asociación de productores o a la Asociación de Productores de Cafés Especiales de Viotá y del Tequendama (Asocavit).

El objetivo del esquema (Figura 6) es poder establecer, de manera clara y rápida, las características principales, los criterios de valoración de cada hacienda y el momento histórico en el que fueron construidas para de esta manera proceder a evaluar cuáles de ellas eventualmente podrían ser declaradas como BIC. Respecto a la información que contiene la ficha conviene aclarar que puesto que el inventario es preliminar, no se ha profundizado en el análisis de materiales y diagnóstico de deterioros.

\section{Fase 2. Caracterización}

Dado que el patrimonio cultural ha demostrado ser una herramienta útil para la recuperación de la identidad, la construcción de tejido social y la reactivación económica, el equipo de trabajo de subproyecto "Gestión cultural del patrimonio y paisaje cultural", compuesto por dos arquitectos, un economista, dos profesionales en el área de turismo y una estudiante de arquitectura que desarrolla su proyecto de grado han realizado visitas, reuniones, encuestas con la Alcaldía, el Ministerio de Cultura, Asociaciones de productores y comunidad local interesada en proteger el patrimonio de su municipio (Ministerio de Cultura, Federación Nacional de Cafeteros, 2012).

Las reuniones tuvieron como objetivo, en primer lugar, informarles acerca de los alcances del subproyecto y escuchar sus necesidades, dudas e inquietudes en relación con la conveniencia o no de lograr declaratorias como BIC, puesto que sin la participación activa de los actores locales ninguna propuesta estará destinada al éxito. Con este fin se han desarrollado algunas encuestas sobre el conocimiento de la comunidad acerca del patrimonio cultural y de la financiación proyectos para su protección por medio de un inventariado y declaratorias a nivel municipal.

Este trabajo conjunto ha sido útil para poder identificar los elementos de valor patrimonial que deberían ser inventariados tales como: petroglifos, un camino real y 12 haciendas cafeteras, junto con un sendero ambiental construido hace más de 25 años por el ingeniero forestal Luis Enrique Acero (2007); asimismo, aquellos bienes de carácter intangible que otro subproyecto está identificando. En la comunidad existe la conciencia de la existencia de bienes de interés cultural y patrimonial; pero antes de la realización de la encuesta desconocían la posibilidad de obtener recursos extras a través de ellos. Ahora, los ven como un medio para poder reactivar la zona, generar nuevos empleos y permitir el desarrollo económico, como ha ocurrido en el caso del paisaje cultural cafetero, que fue incluido en la lista del patrimonio mundial por la Unesco en 2011, y ha permitido la conservación, revitalización, promoción del patrimonio cultural y articulación con el desarrollo regional; así como el apoyo a la sostenibilidad productiva y ambiental.

\section{Discusión}

A partir de la metodología seguida, y una vez identificadas las haciendas y localizadas en el territorio, uno de los principales interrogantes que surgió fue cómo articular los elementos patrimoniales existentes en el territorio: haciendas, petroglifos, caminos reales, etc. Por este motivo, se plantea la idea de pensar el territorio de Viotá como un paisaje cultural o itinerario cultural, de acuerdo con el cumplimiento o no de todos los criterios, y cómo catalogar los hallazgos industriales encontrados en el lugar: por este motivo se planteó la pregunta que da lugar al siguiente apartado.

\section{iltinerario cultural o paisaje industrial?}

Cuando se comenzó el proceso de caracterización se partió de la pregunta de si se trataba de un itinerario cultural o de un paisaje industrial. 

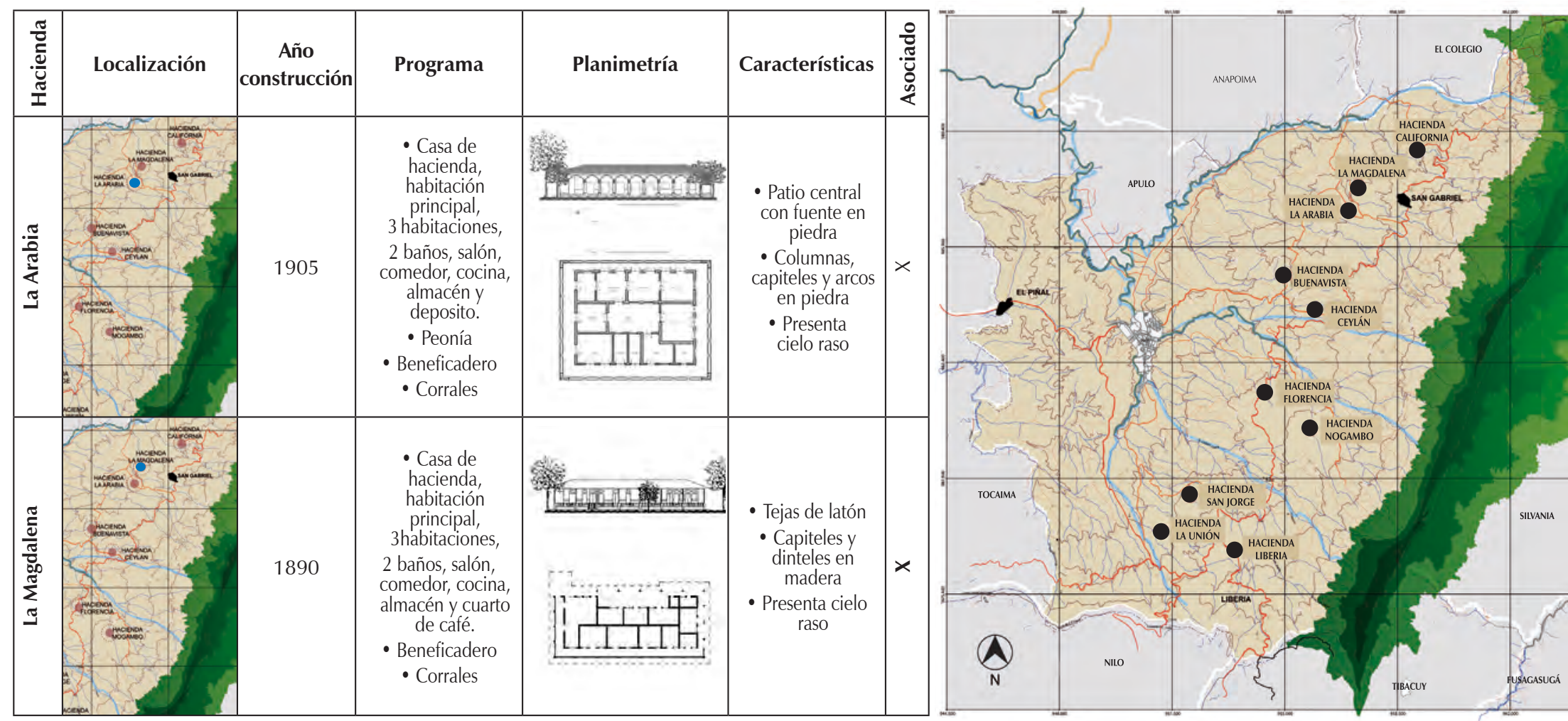

(A) Figura 6. Modelo de ficha de inventario con localización, principales características y criterios de valoración de cada hacienda Fuente: elaboración propia, 2014)

Se tomaron como referencia para establecer las diferencias entre estos conceptos las cartas de la Unesco: Carta de Nizhny Tagil (Icomos, 2003) sobre el patrimonio industrial, y la Carta sobre itinerarios culturales de Icomos, donde el itinerario cultural rescata y enfatiza el de todos y cada uno de los elementos que componen el territorio. El reconocimiento de los itinerarios culturales también contribuye a ilustrar la concepción social contemporánea de los valores del patrimonio cultural como un recurso para el desarrollo social y económico sostenible (Icomos 2008a).

El patrimonio industrial, de acuerdo con la carta mencionada, se define como:

El patrimonio industrial se compone de los restos de la cultura industrial que poseen un valor histórico, tecnológico, social, arquitectónico o científico. Estos restos consisten en edificios y maquinaria, talleres, molinos y fábricas, minas y sitios para procesar y refinar, almacenes y depósitos, lugares donde se genera, se transmite y se usa energía, medios de transporte y toda su infraestructura, así como los sitios donde se desarrollan las actividades sociales relacionadas con la industria, tales como la vivienda, el culto religioso o la educación (Icomos, 2003, p. 1).

Por el tipo de evidencias que se han ido encontrando en el lugar, y por las características de la maquinaria presente en los beneficiaderos, años de importación y estado de conservación es posible que la mejor categoría para encajar el caso del patrimonio cultural presente en Viotá sea el paisaje industrial. Es importante agregar que ambas categorías no se superponen entre sí, sino que el paisaje industrial guarda armonía con el paisaje cultural.

De acuerdo con lo anterior, y con la Fase 1 de identificación, se ha podido reconocer el municipio de Viotá y su relación con la provincia del Tequendama y el departamento de Cundinamarca. En cuanto a la Fase 2 de caracterización se lograron inventariar solo siete de las doce haciendas cafeteras identificadas; ha sido difícil avanzar en la consecución de este objetivo por problemas operativos, desconfianza de algunos de los propietarios que no permiten que sean inventariadas, por las distancias entre ellas y las deficiencias en el sistema vial.

Aunque al ir avanzando en el trabajo se hizo evidente el potencial que tendrían si trabajaran interconectadas como un sistema en red de haciendas articuladas con el camino real que actualmente fue caracterizado por otro miembro del equipo, y los petroglifos de origen panche que se encuentran por toda la zona.

Igualmente, según la información recolectada y consultada, ha sido posible encontrar bienes muebles relacionados con el patrimonio industrial, por lo que se ha tomado como base la Carta de Nizhny Tagil sobre el Patrimonio Industrial (Icomos, 2003), y se está indagando en este sentido, tomando como referencia las experiencias de los paisajes industriales mineros en Andalucía o los astilleros del País Vasco en España, para intentar establecer, de acuerdo con los planes de desarrollo y el esquema de ordenamiento territorial de Viotá, cuál aplica mejor: paisaje cultural, itinerario cultural o paisaje industrial de acuerdo con el alcance previsto para esta fase del proyecto.
(A) Figura 7. Localización de las haciendas cafeteras en el contexto municipal Fuente: Catherine Ballén Torres, 2014. 
De acuerdo con la revisión del estado del arte en temas relacionados con el patrimonio cultural, declaratorias, criterios de valoración, inventarios de BIC, entrevistas con expertos académicos etc., en otros lugares de Colombia ${ }^{4}$ se ha evidenciado que las declaratorias no siempre son la mejor herramienta para la protección y el mantenimiento de los BIC, puesto que en algunos casos estas estrategias legales hacen que los bienes inmuebles caigan en el desuso y abandono por parte de sus propietarios, ya que en muchos casos la normativa es restrictiva en cuanto a nuevos usos, actividades de las que se pueda obtener usufructo y revitalización de los mismos.

Por esta razón es importante y necesario consultar y hacer partícipe a la comunidad afectada en cuanto a ventajas y desventajas para poder entrar en dichos procesos legales, puesto que a fin de cuentas ellos serán los beneficiarios o directos perjudicados de dichas acciones. Porque este abandono genera el deterioro que, a su vez, viene acompañado de procesos de pérdida de memoria y de identidad cultural que en el caso puntual de Viotá es uno de los problemas que se pretende solucionar con esta investigación, además de la cohesión social y la importancia de su capital cultural.

La identificación del territorio y la caracterización e inventario de un BIC son importantes porque permiten a los diferentes actores presentes en un lugar valorar y respetar aquellos elementos que hacen parte de su memoria y que son herramienta fundamental para la construcción de su identidad. Asimismo, el patrimonio cultural es el centro de cualquier actividad económica, sea en turismo o producción agrícola, puesto que permite generar una identidad, un sello de reconocimiento, o cierta propiedad intelectual que se puede transmitir y da un cierto valor simbólico a aquellas personas externas al territorio, que a pesar de pertenecer a dicho lugar lo reconocen.

Darle valor a los otros elementos presentes en ese territorio, tales como el camino real y los petroglifos, incluidos todos aquellos elementos que hacen parte del patrimonio intangible, permitirá avanzar en la tarea de ayudar al municipio de Viotá a recuperar su identidad y sentido de pertenencia por parte de sus habitantes. Acercar a la población del lugar a temas relacionados con el patrimonio cultural, inventarios y declaratorias de bienes de interés cultural, valor agregado de los BIC y vías de financiación ha permitido plan-

4 Un claro ejemplo fue la declaratoria de BIC del casco histórico de Ambalema, Tolima, que actualmente se encuentra en avanzado estado de deterioro y abandonado por parte de los habitantes originales, puesto que la declaratoria lo que hizo fue obligar a que las construcciones no se pudieran actualizar y llevó al centro de Ambalema a un estado prácticamente de momificación. tear espacios de análisis y discusión en comunidad de lo que desea el municipio para sí mismo, y cómo esperan ser reconocidos en el futuro.

\section{Conclusiones}

Para la recomposición del tejido social, que en el caso del municipio de Viotá se vio debilitado y afectado por el conflicto armado, algunas de las oportunidades identificadas fueron la construcción de proyectos productivos que permitan relacionar el municipio con la región tomando como punto partida el patrimonio cultural. La identificación y valoración del territorio para encontrar su significado, y la caracterización e inventario de potenciales bienes de interés cultural es importante porque permite a los diferentes actores presentes en un lugar conocer, valorar y respetar aquellos elementos que hacen parte de su memoria y dan cuenta de su forma de vida y relación con su territorio, siendo herramienta fundamental para la construcción de su identidad. Asimismo, el patrimonio cultural tiene el potencial de servir de centro a cualquier actividad económica, sea en turismo o producción agrícola, puesto que permite ser identificado y diferenciado, tener un sello de reconocimiento, o cierta propiedad intelectual que se puede transmitir, y da un cierto valor simbólico a aquellas personas externas al territorio, y a sus habitantes les permite fortalecer el sentido de pertenencia.

Sin embargo, esta tarea de identificar y valorar los elementos patrimoniales debe contar con la participación y aceptación de los diferentes actores implicados: ciudadanos, propietarios de los bienes de interés cultural, entidades gubernamentales y todas aquellas instituciones que puedan brindar apoyo técnico como instituciones educativas, organizaciones sin ánimo de lucro, etc. Durante el proceso de trabajo en Viotá, esta participación y aceptación por parte de todos los actores no siempre fue activa y, en muchos, casos por miedo, desconfianza o falta de información, no fue posible socializar los objetivos del proyecto ni recoger las inquietudes que podrían haber ayudado a direccionar y fortalecer el proceso en beneficio de todos.

Algunas de las principales barreras que se encontraron para la elaboración de los inventarios fueron: desconocimiento del potencial y valor de sus haciendas y maquinaria existente como bienes de interés cultural, falta de interés en contar con una declaratoria a nivel municipal o nacional, puesto que se ve como un problema que no aporta ningún valor a su propiedad, y la debilidad económica que los obliga a cambiar la vocación productiva de sus haciendas haciendo que las máquinas y los beneficiaderos para el proceso del cultivo del café caigan en desuso y deban ser vendidas o reemplazadas por otro tipo de actividades relacionadas con el cultivo de otros productos que actualmente son más rentables. 
De la misma manera, darle valor a los otros elementos presentes en ese territorio, tales como el camino real y los petroglifos, que permiten articular las haciendas diseminadas por el área rural del municipio, y la inclusión de todos aquellos elementos que hacen parte del patrimonio intangible, permitiría avanzar en la tarea de ayudar a Viotá a recuperar su identidad y a reactivarse económicamente. El acercar a la población del lugar a temas relacionados con el patrimonio cultural, inventarios y declaratorias de Bienes de Interés Cultural, valor agregado de estos y posibles vías de financiación ha permitido plantear espacios de análisis y discusión en comunidad acerca de lo que desea el municipio para sí mismo, y cómo esperan ser reconocidos en el futuro. Sin embargo, no ha sido posible concretar esta tarea por la falta de consenso entre los actores y entre los investigadores que participan en el proyecto.

\section{Referencias}

Acero, L. E. (2007). Viotá: un paraíso en los Andes colombianos: monografía histórica. Bogotá: L.E. Acero Duarte.

Alcaldía de Viotá (2012). Plan de Desarrollo Viotá Territorio de Paz y Prosperidad 20122015. Recuperado de: www.viota-cundinamarca.gov.co.

Colmenares, G. (1987). La formación de la economía colonial. En Ocampo, J. A. Historia económica de Colombia (pp. 2-22). Bogotá: Biblioteca Luis Angel Arango, Biblioteca Virtual. Recuperado de http://www.banrepcultural.org/blaavirtual/economia/histecon/ histecon2a.htm

Conpes (2004). Documento Conpes 3305 de 2004. Sobre lineamientos para optimizar la política de desarrollo urbano. 23 de agosto de 2004. Bogotá. Recuperado de: http:// www.minambiente.gov.co/images/normativa/conpes/2004/Conpes_3305_2004.pdf

Conpes (2014). Documento Conpes 3803 de 2014. Política para la preservación del paisaje cultural en Colombia. 13 de febrero de 2014. Bogotá. Recuperado de: http://paisajeculturalcafetero.org.co/static/files/Conpes1.pdf

Decreto 69 de 2011 [Alcaldía de Viotá]. Por el cual se ajusta el esquema de ordenamiento territorial del municipio de Viotá adoptado mediante el acuerdo 027 de 2001. 21 de diciembre de 2011.

Decreto 763 de 2009 [Presidencia de la República de Colombia]. Por el cual se reglamentan parcialmente las leyes 814 de 2003 y 397 de 1997 modificada por medio de la Ley 1185 de 2008, en lo correspondiente al Patrimonio Cultural de la Nación de naturaleza material. 10 de marzo de 2009. Recuperado de http://www.alcaldiabogota.gov. co/sisjur/normas/Norma1.jsp?i=35447\#0

Icomos (1967). Normas de Quito. Quito (Ecuador). Recuperado de: http://www.icomos. org/charters/quito.htm

Icomos (2003). Carta de Nizhny Tagil sobre el Patrimonio Industrial. Asamblea Nacional del TICCIH. Moscú (Rusia).

Icomos (2008a). Carta de Itinerarios Culturales. $16^{a}$ Asamblea General del Icomos, Quebec (Canadá). Recuperado de: http://www.international.icomos.org/charters/culturalroutes sp.pdf
Icomos (2008b). Carta de Burra. Carta de ICOmos Australia para sitios de significación cultural. Recuperado de: http://www.international.icomos.org/charters/burra1999 spa.pdf

Ley 1185 de 2008 (Ley General de Cultura) [Congreso de la República]. Por la cual se modifica y adiciona la Ley 397 de 1997 (Ley General de Cultura) y se dictan otras disposiciones. 12 de marzo de 2008. Recuperado de http://www.alcaldiabogota.gov. co/sisjur/normas/Norma1.jsp?i=29324

Ley 1448 de 2011 [Congreso de la República]. Por la cual se dictan medidas de atención, asistencia y reparación integral a las víctimas del conflicto armado interno y se dictan otras disposiciones. 10 de junio de 2011. Recuperado de http://www.alcaldiabogota. gov.co/sisjur/normas/Norma1.jsp?i=43043

Ley 1454 de 2011 [Congreso de Colombia] Por la cual se dictan normas orgánicas sobre: ordenamiento territorial y se modifican otras disposiciones. 28 de junio de 2011. Recuperado de http://wsp.presidencia.gov.co/Normativa/Leyes/Documents/ley145428062011.pdf

Ley 388 de 1997 [Congreso de Colombia]. Por la cual se modifica la Ley 9 de 1989, y la Ley 2 de 1991 y se dictan otras disposiciones. 18 de julio de 1997. Recuperado de http://www.alcaldiabogota.gov.co/sisjur/ normas/Norma1.jsp?i=339

Ley 397 de 1997 [Congreso de Colombia]. Por la cual se desarrollan los artículos 70, 71 y 72 y demás artículos concordantes de la Constitución Política y se dictan normas sobre patrimonio cultural, fomentos y estímulos a la cultura, se crea el Ministerio de la Cultura y se trasladan algunas dependencias. 7 de agosto de 1997. Recuperado de http://www.alcaldiabogota.gov.co/ sisjur/normas/Norma1.jsp?i $=337$

Martínez Herrera, O. J. (2016 enero-junio). Patrimonio cultural y turismo, una alternativa de desarrollo: caso Viotá, Cundinamarca. Turismo y Sociedad, XVIII, 99-116. Recuperado de: http://revistas.uexternado.edu.co/index.php/tursoc/article/ view/4621
Ministerio de Cultura, Federación Nacional de Cafeteros (2012). Guía para la incorporación del paisaje cultural cafetero en la revisión y ajuste de los planes de ordenamiento territorial (POT, PBOT, EOT). Bogotá: Escala. Recuperado de: http://paisajeculturalcafetero.org.co/static/files/cartilla_pot.pdf

Ministerio de Cultura (2005). Manual para inventarios de bienes culturales inmuebles. Bogotá: Imprenta Nacional.

Ministerio de Cultura (2010). P-Patrimonio cultural para todos: una guía de fácil comprensión. Bogotá: Imprenta Nacional.

Ministerio de Cultura (2011). Formulación e implementación de planes especiales de manejo y protección de bienes inmuebles de interés cultural. Bogotá: Nomos Impresores.

Téllez, G. (1997). Casa de Hacienda. Arquitectura del campo colombiano. Bogotá: Villegas Editores.

Throsby, D. (2008). Economía y cultura. México: Gestión Cultural. Consejo Nacional para la Cultura y las Artes (Conalculta).

Tocancipá-Falla, J. (2006, diciembre). Cafés en la "ciudad blanca": identidad, crisis cafetera y el restablecimiento del orden social en Colombia. Revista de estudios sociales, 25, 67-79. Recuperado de: http://res.uniandes. edu.co/view.php/281/view.php

Unesco (1931). La Carta de Atenas. Recuperado de: http://ipce.mcu.es/pdfs/1931_Carta_Atenas.pdf

Unesco (1964). La Carta de Venecia. Venecia. Recuperado de: http://www.unesco.org/ culture/natlaws/media/pdf/guatemala/guatemala_carta_venecia_1964_spa_orof.pdf

Unesco (1972). Convención sobre la protección del patrimonio mundial, cultural y natural. Recuperado de: http://whc.unesco. org/archive/convention-es.pdfMinisterio de Cultura. (2011). Formulación e Implementación de Planes Especiales de Manejo y Protección de Bienes Inmuebles de Interés Cultural. Bogotá: Nomos Impresores. 
La postulación de un artículo a la Revista de Arquitectura indica que- el o los autores certifican que conocen y aceptan la política editorial, para lo cual firmarán en original y remitirán el formato RevArq FP00 Carta de originalidad.

La Revista de Arquitectura maneja una política de Autoarchivo VERDE, según las directrices de SHERPA/RoMEO, por lo cual el autor puede:

- Pre-print del autor: Archivar la versión pre-print (la versión previa a la revisión por pares)

- Post-print del autor: Archivar la versión post-print (la versión final posterior a la revisión por pares)

- Versión de editor/PDF: Archivar la versión del editor - PDF/HTML/XLM en la maqueta de la Revista de Arquitectura.

El Autoarchivo se debe hacer respetando la licencia de acceso abierto, la integridad y la imagen de la Revista de Arquitectura, también se recomienda incluir la referencia, el vínculo electrónico y el DOI.

El autor o los autores son los titulares del Copyright (c) del texto publicado y la Editorial de la Revista de Arquitectura solicita la firma de una autorización de reproducción del artículo (RevArq FP03 Autorización reproducción), la cual se acoge a la licencia CC, donde se expresa el derecho de primera publicación de la obra.

La Revista de Arquitectura se guía por las normas internacionales sobre propiedad intelectual y derechos de autor, y de manera particular el artículo 58 de la Constitución Política de Colombia, la Ley 23 de 1982 y el Acuerdo 172 del 30 de septiembre de 2010 (Reglamento de propiedad intelectual de la Universidad Católica de Colombia).

Para efectos de autoría y coautoría de artículos se diferencian dos tipos: "obra en colaboración" y "obra colectiva". La primera es aquella cuya autoría corresponde a todos los participantes al ser fruto de su trabajo conjunto. En este caso, quien actúa como responsable y persona de contacto debe asegurar que quienes firman como autores han revisado y aprobado la versión final, y dan consentimiento para su divulgación. La obra colectiva es aquella en la que, aunque participan diversos colaboradores, hay un autor que toma la iniciativa, la coordinación y realización de dicha obra. En estos casos, la autoría corresponderá a dicha persona (salvo pacto en contrario) y será suficiente únicamente con su autorización de divulgación.

El número de autores por artículo debe estar justificado por el tema, la complejidad y la extensión, y no deberá ser superior a la media de la disciplina, por lo cual se recomienda que no sea mayor de cinco. El orden en que se enuncien corresponderá a los aportes de cada uno a la construcción del texto, se debe evitar la autoría ficticia o regalada. Si se incluyen más personas que trabajaron en la investigación se sugiere que sea en calidad de colaboradores o como parte de los agradecimientos. La Revista de Arquitectura respetará el número y el orden en que figuren en el original remitido. Si los autores consideran necesario, al final del artículo pueden incluir una breve descripción de los aportes individuales de cada uno de firmantes.

La comunicación se establece con uno de los autores, quien a su vez será el responsable de informar a los demás autores de las notificaciones emitidas por la Revista de Arquitectura.

En virtud de mantener el equilibro de las secciones y las mismas oportunidades para todos los participantes, un mismo autor puede postular dos o más artículos de manera simultánea; si la decisión editorial es favorable y los artículos son aceptados, su publicación se realizará en números diferentes.

\section{(A) Acceso abierto}

La Revista de Arquitectura, en su misión de divulgar la investigación y apoyar el conocimiento y la discusión en los campos de interés, proporciona acceso abierto, inmediato e irrestricto a su contenido de manera gratuita mediante la distribución de ejemplares impresos y digitales. Los interesados pueden leer, descargar, guardar, copiar y distribuir, imprimir, usar, buscar o referenciar el texto completo o parcial de los artículos o la totalidad de la Revista de Arquitectura.

\section{(1) (3)}

Esta revista se acoge a la licencia Creative Commons (CC BYNC de Atribución - No comercial 4.0 Internacional): "Esta licencia permite a otros entremezclar, ajustar y construir a partir de su obra con fines no comerciales, y aunque en sus nuevas creaciones deban reconocerle su autoría y no puedan ser utilizadas de manera comercial, no tienen que estar bajo una licencia con los mismos términos".

La Revista de Arquitectura es divulgada en centros y grupos de investigación, en bibliotecas y universidades, y en las principales facultades de Arquitectura, mediante acceso abierto a la versión digital y suscripción anual al ejemplar impreso o por medio de canje, este último se formaliza mediante el formato RevArq FP20 Canjes.

Para aumentar su visibilidad y el impacto de los artículos, se envían a bases de datos y sistemas de indexación y resumen (SIR) y, asimismo, pueden ser consultados y descargados en la página web de la revista.

La Revista de Arquitectura no maneja cobros, tarifas o tasas de publicación de artículo (Article Processing Charge-APC), o por el sometimiento de textos a la publicación.

\section{(1) Ética y buenas prácticas}

La Revista de Arquitectura se compromete a cumplir y respetar las normas éticas en todas las etapas del proceso de publicación. Los autores de los artículos publicados darán cumplimiento a los principios éticos contenidos en las diferentes declaraciones y legislaciones sobre propiedad intelectual y derechos de autor específicos del país donde se realizó la investigación. En consecuencia, los autores de los artículos postulados y aceptados para publicar, que presentan resultados de investigación, deben firmar la declaración de originalidad (formato RevArq FP00 Carta de originalidad).

La Revista de Arquitectura reconoce y adopta los principios de transparencia y buenas prácticas descritos por COPE, "Principles of Transparency and Best Practice in Scholarly Publishing" (2015).

El equipo editorial tiene la obligación de guardar la confidencialidad acerca de los artículos recibidos, y abstenerse de usar en sus propias investigaciones datos, argumentos o interpretaciones hasta tanto el artículo no sea publicado. También debe ser imparcial y gestionar los artículos de manera adecuada y en los plazos establecidos. La selección de revisores se hará con objetividad y estos deberán responder a la temática del artículo.

El editor, los autores y los revisores deben seguir las normas éticas internacionales definidas por el Committee on Publication Ethics (COPE), con el fin de evitar casos de:

- Fabricación, falsificación u omisión de datos.

- Plagio y autoplagio.

- Publicación redundante, duplicada o fragmentada.

- Omisión de referencias a las fuentes consultadas.

- Utilización de contenidos sin permiso o sin justificación.

- Apropiación individual de autoría colectiva.

- Cambios de autoría.

- Conflicto de interés (CDI) no revelado o declarado.

- Otras que pudieran surgir en el proceso de investigación y publicación. La fabricación de resultados se genera al mostrar datos inventados por los autores; la falsificación resulta cuando los datos son manipulados y cambiados a capricho de los autores; la omisión se origina cuando los autores ocultan deliberadamente un hecho o dato. El plagio se da cuando un autor presenta como ideas propias datos creados por otros. Los casos de plagio son los siguientes: copia directa de un texto sin entrecomillar o citar la fuente, modificación de algunas palabras del texto, paráfrasis y falta de agradecimientos; el autoplagio se da cuando el mismo autor reutiliza material propio que ya fue publicado, pero sin indicar la referencia al trabajo anterior. La revista se apoya en herramientas digitales que detectan cualquiera de estos casos en los artículos postulados, y es labor de los editores y revisores velar por la originalidad y fidelidad en la citación. La publicación redundante o duplicada se refiere a la copia total, parcial o alterada de un trabajo ya publicado por el mismo autor

En caso de sospechar de alguna mala conducta se recomienda seguir los diagramas de flujo elaborados por COPE (2008), con el fin de determinar las acciones correspondientes.

La Revista de Arquitectura se reserva el derecho de retractación de publicación de aquellos artículos que, posterior a su publicación, se demuestre que presentan errores de buena fe, o cometieron fraudes o malas prácticas científicas. Esta decisión se apoyará en "Retraction Guidelines" (COPE, 2009). Si el error es menor, este se podrá rectificar mediante una nota editorial de corrección o una fe de erratas. Los autores también tienen la posibilidad de solicitar la retractación de publicación cuando descubran que su trabajo presenta errores graves. En todos los casos se conservará la versión electrónica y se harán las advertencias de forma clara e inequívoca.

\section{(A) Privacidad y manejo de la información.} Habeas Data

Para dar cumplimiento a lo previsto en el artículo 10 del Decreto 1377 de 2013, reglamentario de la Ley 1581 de 2012, y según el Acuerdo 002 del 4 de septiembre de 2013 de la Universidad Católica de Colombia, "por el cual se aprueba el manual de políticas de tratamiento de datos personales":

La Universidad Católica de Colombia, considerada como responsable o encargada del tratamiento de datos personales, manifiesta que los datos personales de los autores, integrantes de los comités y pares revisores, se encuentran incluidos en nuestras bases de datos; por lo anterior, y en cumplimiento de las disposiciones legales vigentes, la Universidad solicitará siempre su autorización, para que en desarrollo de sus funciones propias como Institución de Educación Superior, en especial las relacionadas con la docencia, la extensión y la investigación, la Universidad Católica de Colombia pueda recolectar, recaudar, almacenar, usar, circular, suprimir, procesar, intercambiar, compilar, dar tratamiento, actualizar, transmitir o transferir a terceros países y disponer de los datos que le han suministrado y que han sido incorporados en las bases de datos de todo tipo que reposan en la Universidad.

La Universidad Católica de Colombia queda autorizada, de manera expresa e inequívoca, en los términos señalados por el Decreto 1377 de 2013, para mantener y manejar la información de nuestros colaboradores (autores, integrantes de los diferentes comités y pares revisores); así mismo, los colaboradores podrán ejercer sus derechos a conocer, actualizar, rectificar y suprimir sus datos personales, para lo cual se han dispuesto las siguientes cuentas de correo electrónico: 
La Revista de Arquitectura recibe artículos de manera permanente. Los artículos se procesan a medida que se postulan, dependiendo el flujo editorial de cada sección.

El idioma principal es el español, y como opcionales están definidos el inglés, el portugués y el francés; los textos pueden ser escritos y presentados en cualquiera de estos.

Los artículos postulados deben corresponder a las categorías universalmente aceptadas como producto de investigación, ser originales e inéditos y sus contenidos responder a criterios de precisión, claridad y brevedad.

Como punto de referencia se pueden tomar las tipologías y definiciones del Índice Bibliográfico Nacional, Publindex (2010) que se describen la continuación:

1. Artículo de revisión: documento resultado de una investigación terminada donde se analizan, sistematizan e integran los resultados de investigaciones publicadas o no publicadas, sobre un campo en ciencia o tecnología, con el fin de dar cuenta de los avances y las tendencias de desarrollo. Se caracteriza por presentar una cuidadosa revisión bibliográfica de por lo menos 50 referencias.
2. Artículo de investigación científica y tecnológica: documento que presenta, de manera detallada, los resultados originales de proyectos terminados de investigación. La estructura generalmente utilizada contiene cuatro apartes importantes: introducción, metodología, resultados y conclusiones.

3. Artículo de reflexión: documento que presenta resultados de investigación terminada desde una perspectiva analítica, interpretativa o crítica del autor, sobre un tema específico, recurriendo a fuentes originales.

En todos los casos se debe presentar la información suficiente para que cualquier investigador pueda reproducir la investigación y confirmar o refutar las interpretaciones defendidas.

También se pueden presentar otro tipo de documentos diferentes a los anteriormente descritos, como pueden ser: artículo corto, reporte de caso, revisión de tema, documento resultado de la revisión crítica de la literatura sobre un tema en particular, cartas al editor, traducción, documento de reflexión no derivado de investigación, reseña bibliográfica, así como proyectos de arquitectura o urbanismo, entre otros

\section{(A) Instrucciones para postular artículos}

Postular el artículo en la página web de la Revista de Arquitectura y adjuntar comunicación escrita dirigida al editor RevArq_FP00 Carta de originalidad (debidamente firmada por todos los autores en original); de igual manera, se debe diligenciar el formato de hoja de vida RevArq FP01 Hoja de Vida (una por cada autor).

En la comunicación escrita el autor expresa que conoce y acepta la política editorial de la Revista de Arquitectura, que el artículo no está postulado para publicación simultáneamente en otras revistas u órganos editoriales y que no existe conflicto de intereses (ver modelo RevArq FP06 CDI) y que, de ser aceptado, concederá permiso de primera publicación, no exclusiva a nombre de la Universidad Católica de Colombia como editora de la revista.

Los artículos deben tener en cuenta las siguientes recomendaciones:

- En la primera página del documento se debe incluir:

Título: no exceder 15 palabras.

Subtítulo: opcional, complementa el título o indica las principales subdivisiones del texto.

Nombre del autor o autores: nombres y apellidos completos o según modelo de citación adoptado por el autor para la normalización de los nombres del investigador. Como nota al pie (máximo 150 palabras): formación académica, experiencia profesional e investigativa, vinculación laboral, código ORCID, premios o reconocimientos, publicaciones representativas e información de contacto, correo electrónico.

Filiación institucional: debajo del nombre se debe declarar la institución en la cual se desarrolló el producto, de la cual recibió apoyo o aquella que respalda el trabajo investigativo.

Resumen: debe ser analítico, se redacta en un solo párrafo, da cuenta del tema, el objetivo, la metodología, los resultados y las conclusiones; no debe exceder las 150 palabras.

Palabras clave: cinco palabras o grupo de palabras, ordenadas alfabéticamente y que no se encuentren en el título o subtítulo; estas sirven para clasificar temáticamente al artículo. Se recomienda emplear principalmente palabras definidas en el tesauro de la Unesco (http:// databases.unesco.org/thessp/), en el tesauro de Arte \& Arquitectura (C) (www.aatespanol.cl), o Vitruvio (http://vocabularyserver.com/vitruvio/)

También se recomienda incluir título, resumen y palabras clave en segundo idioma.

- La segunda página y siguientes deben tener en cuenta:

El cuerpo del artículo generalmente se divide en: Introducción, Metodología, Resultados y Discusión de resultados; posteriormente se presentan las Conclusiones, y luego las Referencias bibliográficas y los Anexos (método IMRYD). Las tablas y figuras se deben incorporar en el texto.

Descripción del proyecto de investigación: en la introducción se debe describir el tipo de artículo y brevemente el marco investigativo del cual es resultado y diligenciar el formato (RevArq FP02 Info Proyectos de Investigación).

TEXTO: todas las páginas deben venir numeradas y con el título de artículo en la parte superior de la página. Márgenes de $3 \mathrm{~cm}$ por todos los lados, interlineado doble, fuente Arial o Times New Roman de 12 puntos, texto justificado (Ver plantilla para presentación de artículos). La extensión de los artículos debe ser de alrededor de 5.000 palabras ( \pm 20 páginas, incluyendo gráficos, tablas, referencias, etc.); como mínimo 3.500 y máximo 8.000 palabras. Se debe seguir el estilo vigente y recomendado en el Manual para Publicación de la American Psychological Association (APA). (Para mayor información véase http://www.apastyle.org/)
Citas y notas al pie: las notas aclaratorias o notas al pie no deben exceder cinco líneas o 40 palabras, de lo contrario estas deben ser incorporadas al texto general. Las citas pueden ser:

Corta: (con menos de 40 palabras) se incorporan al texto y pueden ser: textuales (se encierran entre dobles comillas), parafraseo o resumen (se escriben en palabras del autor dentro del texto).

Cita textual extensa: (mayor de 40 palabras) debe ser dispuesta en un renglón y un bloque independiente con sangrías y omitiendo las comillas, no olvidar en ningún caso la referencia del autor (Apellido, año, página).

Referencias: como modelo para la construcción de referencias se emplea el estilo recomendado en el Manual para Publicación de la American Psychological Association (APA) (http://www.apastyle.org/).

Siglas: en caso de emplear siglas en el texto, las figuras o las tablas, se debe proporcionar la equivalencia completa la primera vez que se empleen y encerrarlas entre paréntesis. En el caso de citar personajes reconocidos se deben colocar nombres o apellidos completos, nunca emplear abreviaturas.

Figuras y tablas: las figuras (gráficos, diagramas, ilustraciones, planos, mapas o fotografías) y las tablas deben ir numeradas y contener título o leyenda explicativa relacionada con el tema del artículo, que no exceda las 15 palabras (Figura 1. xxxxx, Tabla 1. xxxx, etc.) y la procedencia (fuente: autor o fuente, año, página). Estas se deben referenciar en el texto de forma directa o entre paréntesis; se recomienda hacerlo con referencias cruzadas.

También se deben entregar en medio digital, independiente del texto, en formatos editables o abiertos. La marcación de los archivos debe corresponder a la incluida en el texto. Según la extensión del artículo se deben incluir de 5 a 10 gráficos. Ver guía para la búsqueda de imágenes de dominio público o bajo licencias Creative Commons (CC).

El autor es el responsable de adquirir los derechos o las autorizaciones de reproducción a que haya lugar para imágenes o gráficos tomados de otras fuentes, así como de entrevistas o material generado por colaboradores diferentes a los autores; de igual manera, se debe garantizar la protección de datos e identidades para los casos que sea necesario.

FotografíA: pueden ser entregadas en original para ser digitalizadas, de lo contrario se deben digitalizar con una resolución igual o superior a 300 dpi para imágenes a color y 600 para escala de grises. Los formatos de las imágenes pueden ser TIFF, PSD o JPG, y deben cumplir con las características expresadas en el punto anterior (figuras).

Planimetría: se debe entregar la planimetría original en medio digital, en lo posible en formato CAD, y sus respectivos archivos de plumas o en PDF; de no ser posible, se deben hacer impresiones en tamaño carta con las referencias de los espacios mediante numeración y lista adjunta. Deben tener escala gráfica, escala numérica, norte, coordenadas y localización. En lo posible, no deben contener textos, achurados o tramas.

Para más detalles, consultar el documento RevArq Parámetros para Autores Descripción en el portal web de la Revista de Arquitectura

\section{Beneficios}

Como reconocimiento a los autores, se les hará envío postal de dos ejemplares de la edición impresa sin ningún costo y entregada en la dirección consignada en el formato de hoja de vida (RevArq FP01); adicionalmente, se enviará el vínculo para la descarga de la versión digital.

También se enviará una constancia informativa en la que se relaciona la publicación del artículo y, de manera opcional, se pueden detallar las fechas del proceso editorial y el arbitraje realizado. 
La selección de revisores se realiza de acuerdo con los siguientes criterios:

- Afinidad temática.

- Formación académica.

- Experiencia investigativa y profesional.

- Producción editorial en revistas similares o en libros resultado de investigación.

El proceso de arbitraje se basa en los principios de equidad e imparcialidad, y en los criterios de calidad y pertinencia.

El desarrollo de la revisión se realiza según el formato (RevArq FP10 Evaluación de artículos) y las observaciones que el revisor considere necesarias en el cuerpo del artículo. En cualquiera de los conceptos que emita el revisor (Aceptar, Publicable con modificaciones, Reevaluable o No publicable), y como parte de la labor formativa y de comunidad académica, el revisor hará sugerencias para mejorar el documento. El revisor podrá solicitar una nueva relectura del artículo después de los ajustes realizados por el autor.

El revisor también deberá diligenciar el formato RevArq FP01 Hoja de Vida, con el fin de certificar y soportar el proceso de revisión ante los SIR que así lo soliciten.

En el proceso de arbitraje se emplea el método doble ciego, los nombres del revisor no serán conocidos por el autor y viceversa. Con el fin de garantizar el anonimato del autor, al artículo postulado se le han podido suprimir nombres, instituciones o imágenes que puedan ser asociadas de manera directa al autor.

Aunque se procura el anonimato, una vez recibida la invitación como par revisor del artículo, el revisor debe cerciorarse de que no exista conflicto de intereses (CDI) o alguna limitante que afecte la revisión o que pueda ser vista como tal (lazos familiares, amistad o enemistad, vínculos contractuales o laborales, posiciones éticas, etc.), de presentarse esta situación se notificara al editor. (Ver modelo RevArq FP06 CDI).

Dada la confidencialidad del proceso de revisión, y considerando los derechos de autor y de propiedad intelectual que pueda haber sobre el material que se entrega, el revisor se compromete a mantener en absoluta reserva su labor, a limitar el uso de la obra entregada solo para el propósito designado y a devolver la documentación remitida una vez concluya la actividad.

El tiempo establecido para las revisiones de pares es de máximo un mes a partir de la confirmación de la recepción de la documentación. Ese plazo podrá ser modificado de mutuo acuerdo entre el editor y el revisor, siempre y cuando no afecte la periodicidad de la revista, la impresión o el tiempo para emitir una respuesta al autor. Los revisores se acogerán a "COPE Ethical Guidelines for Peer Reviewers" de COPE.

\section{Beneficios}

Como retribución a los revisores se les hará envío postal de un ejemplar de la edición impresa sin ningún costo y entregada en la dirección consignada en el formato de hoja de vida. También, si es de interés para el revisor, podrá hacer la solicitud de alguna de las publicaciones editadas y presentes en el catálogo de publicaciones de la UNIVERSIDAD CATÓLICA DE COLOMBIA, previa aprobación de la Editorial y sujeto a la disponibilidad.

Si lo desea tendrá derecho a una constancia de la colaboración en la revisión de artículos, la cual solo contendrá el periodo en el cual se realizó la actividad. También tendrá la posibilidad de aceptar o no la publicación de su nombre, nacionalidad y nivel máximo de formación en la página web de la Revista de Arquitectura en su calidad de colaborador.

\section{A) Proceso de revisión por pares}

Luego de la postulación del artículo, el editor de la Revista de Arquitectura selecciona y clasifica los artículos que cumplen con los requisitos establecidos en las directrices para los autores. El editor podrá rechazar en primera instancia artículos, sin recurrir a un proceso de revisión, si los considera de baja calidad o por presentar evidencias de faltas éticas o documentación incompleta.

Los artículos se someterán a un primer dictamen del editor, de los editores de sección y del Comité Editorial, teniendo en cuenta:

- Afinidad temática, relevancia del tema y correspondencia con las secciones definidas.

- Respaldo investigativo.

- Coherencia en el desarrollo del artículo, así como una correcta redacción y ortografía.

- Relación entre las figuras y tablas con el texto del artículo.
En esta revisión se verificará el nivel de originalidad mediante el uso de software especializado (Ithenticate o similar) y recursos digitales existentes para tal fin, también se observará la coherencia y claridad en los apartados del documento (modelo IMRYD), la calidad de las fuentes y la adecuada citación, esto quedará consignado en el formato (RevArq FP09 Revisión de artículos); esta información será cargada a la plataforma de gestión editorial y estará a disposición del autor.

En caso de que el artículo requiera ajustes preliminares, será devuelto al autor antes de ser remitido a revisores. En este caso, el autor tendrá veinte días para remitir nuevamente el texto con los ajustes solicitados.

Después de la preselección se asignan mínimo dos revisores especializados, quienes emitirán su concepto utilizando el formato (RevArq FP10 Evaluación de artículos) y las anotaciones que consideren oportunas en el texto; en esta etapa se garantizará la confidencialidad y el anonimato de autores y revisores (modalidad doble ciego)

Del proceso de revisión se emite uno de los siguientes conceptos que será reportado al autor:

- Aceptar el envío: con o sin observaciones.

- Publicable con modificaciones: se podrá sugerir la forma más adecuada para una nueva presentación, el autor puede o no aceptar las observaciones según sus argumentos. Si las acepta, cuenta con quince días para realizar los ajustes pertinentes.

- Reevaluable: cumple con algunos criterios y debe ser corregido. Es necesario hacer modificaciones puntuales y estructurales al artículo. En este caso, el revisor puede aceptar o rechazar hacer una nueva lectura del artículo luego de ajustado.

- No publicable: el autor puede volver a postular el artículo e iniciar nuevamente el proceso de arbitraje, siempre y cuando se evidencien los ajustes correspondientes.

En el caso de presentarse diferencias sustanciales y contradictorias en los conceptos sobre la recomendación del revisor, el editor remitirá el artículo a un revisor más o a un miembro del Comité Editorial quien podrá actuar como tercer árbitro, con el fin de tomar una decisión editorial sobre la publicación del artículo.

Los autores deberán considerar las observaciones de los revisores o de los editores, y cada corrección incorporada u omitida debe quedar justificada en el texto o en una comunicación adjunta. En el caso que los autores omitan las indicaciones realizadas sin una argumentación adecuada, el artículo será devuelto y no se dará por recibido hasta que no exista claridad al respecto.

El editor respetará la independencia intelectual de los autores y a estos se les brindará el derecho de réplica en caso de que los artículos hayan sido evaluados negativamente y rechazados.

Los autores, con su usuario y contraseña, podrán ingresar a la plataforma de Gestión Editorial, donde encontrarán los conceptos emitidos y la decisión sobre el artículo.

El editor y el Comité Editorial se reservan el derecho de acepta o no la publicación del material recibido. También se reservan el derecho de sugerir modificaciones de forma, ajustar las palabras clave o el resumen y de realizar la corrección de estilo. El autor conocerá la versión final del texto antes de la publicación oficial del mismo.

Cuando un artículo es aceptado para su publicación, el autor debe firmar la autorización de reproducción (RevArq FP03 Autorización reproducción). Para más información ver: Política de derechos de autor

\section{Notas aclaratorias:}

La Revista de Arquitectura publica un número limitado de artículos por volumen y busca el equilibrio entre las secciones, motivo por el cual, aunque un artículo sea aceptado o continúe en proceso de revisión, podrá quedar aplazado para ser publicado en un próximo número; en este caso, el autor estará en la posibilidad de retirar la postulación del artículo o de incluirlo en el banco de artículos del próximo número.

El editor y los editores de sección de la Revista de Arquitectura son los encargados de establecer contacto entre los autores y revisores, ya que estos procesos se realizan de manera anónima. 
A favela é um cenário: tematização e cenarização nas favelas cariocas

ن் La favela es un escenario: la tematización y escenarización en las favelas de Río

The favela as a setting: Thematization and scenarization in the favelas of Rio de Janeiro

Sergio-Moraes-Rego Fagerlande

Gestión cultural del patrimonio en Viotá, Cundinamarca

De la utopía a la distopía doméstica. La creación de la vivienda modelo norteamericana

From utopia to domestic dystopia. The creation of the American model housing

Da utopia à distopia doméstica. A criação da moradia modelo norte-americana

Carlos Santamarina-Macho

La varanda gourmet brasileña: arquitectura hedonista y distinción social

The Brazilian "varanda gourmet": Hedonistic architecture and social distinction

A varanda gourmet brasileira: arquitetura hedonista diferenciação social

Bruno Cruz-Petit, Alejandro Pérez-Duarte Fernández

Techo plantado como dispositivo de climatización pasiva en el trópico

(j) Green roofs as a passive cooling device in the tropics

Telhados verdes como dispositivo de climatização passiva no Trópico

Iván Osuna-Motta, Carlos Herrera-Cáceres, Oswaldo López-Bernal

Criterios de integración de energía solar activa en arquitectura. Potencial tecnológico y consideraciones proyectuales

Criteria for the architectural integration of active solar energy. Technological potential and design attitudes

Critérios de integração de energia solar ativa em arquitetura. Potencial tecnológico e considerações projetuais

Esteban Zalamea-León, Felipe Quesada

Prototipos flexibles. Proyecto habitacional en el barrio popular Buenos Aires (Soacha)

Flexible prototypes. Housing project in the poor neighborhood of Buenos Aires (Soacha)

Protótipos flexíveis. Projeto habitacional no bairro popular Buenos Aires (Soacha)

Mildred Paola Laiton-Suárez

La pedagogía del taller en la enseñanza de la arquitectura. Una aproximación cultural y material al caso francés (siglos XIX y XX)

La pédagogie de l'atelier dans l'enseignement de l'architecture en France aux XIXe et $\mathrm{XXe}$ siècles, une approche culturelle et matérielle

Pedagogy of the workshop in the teaching of architecture. A cultural and material approach to the French case (19th and 20th centuries)

A pedagogia do ateliê no ensino da arquitetura. Uma aproximação cultural e material ao caso francês (séculos XIX e XX)

Guy Lambert

Traductores:

Andrés Ávila-Gómez

Diana Carolina Ruiz 